\title{
Applicability of Artificial Neural Networks to Predict Mechanical and Permeability Properties of Volcanic Scoria-Based Concrete
}

\author{
Aref M. al-Swaidani ${ }^{1}{ }^{1}$ and Waed T. Khwies $^{2}$ \\ ${ }^{1}$ Associate Professor, Faculty of Architectural Engineering, Arab International (Formerly European) University, Damascus, Syria \\ ${ }^{2}$ Lecturer, Faculty of Information Technology, Arab International (Formerly European) University, Damascus, Syria
}

Correspondence should be addressed to Aref M. al-Swaidani; aydlswaidani@yahoo.fr

Received 30 July 2018; Accepted 26 September 2018; Published 25 October 2018

Guest Editor: Tayfun Dede

Copyright (C) 2018 Aref M. al-Swaidani and Waed T. Khwies. This is an open access article distributed under the Creative Commons Attribution License, which permits unrestricted use, distribution, and reproduction in any medium, provided the original work is properly cited.

\begin{abstract}
Numerous volcanic scoria (VS) cones are found in many places worldwide. Many of them have not yet been investigated, although few of which have been used as a supplementary cementitious material (SCM) for a long time. The use of natural pozzolans as cement replacement could be considered as a common practice in the construction industry due to the related economic, ecologic, and performance benefits. In the current paper, the effect of VS on the properties of concrete was investigated. Twenty-one concrete mixes with three w/b ratios $(0.5,0.6$, and 0.7$)$ and seven replacement levels of VS $(0 \%, 10 \%, 15 \%, 20 \%, 25 \%, 30 \%$, and $35 \%)$ were produced. The investigated concrete properties were the compressive strength, the water permeability, and the concrete porosity. Artificial neural networks (ANNs) were used for prediction of the investigated properties. Feed-forward backpropagation neural networks have been used. The ANN models have been established by incorporation of the laboratory experimental data and by properly choosing the network architecture and training processes. This study shows that the use of ANN models provided a more accurate tool to capture the effects of five parameters (cement content, volcanic scoria content, water content, superplasticizer content, and curing time) on the investigated properties. This prediction makes it possible to design VS-based concretes for a desired strength, water impermeability, and porosity at any given age and replacement level. Some correlations between the investigated properties were derived from the analysed data. Furthermore, the sensitivity analysis showed that all studied parameters have a strong effect on the investigated properties. The modification of the microstructure of VS-based cement paste has been observed, as well.
\end{abstract}

\section{Introduction}

Concrete is the most widely used building material around the world because of the economic and widespread availability of its constituents, its versatility, its durability, and its adaptability [1]. Ordinary Portland Cement (OPC) concrete is a composite material, and its constituents are cement mixed with water, fine-grained aggregate (sand), and coarsegrained aggregate consisting of natural gravel or crushed stones [2]. The considerable amount of carbon dioxide $\left(\mathrm{CO}_{2}\right)$ liberated during the production of Portland cement, the most commonly used hydraulic cement, is of a greater concern. On average, about 1 tonne of $\mathrm{CO}_{2}$ is liberated per tonne of Portland cement produced [1].

The use of mineral admixtures such as pozzolans in concrete is now widespread due to many economic, ecological, and performance-related benefits $[3,4]$. The term "pozzolan" is originally from the town of Pozzuoli, northeast of Naples in Italy, where pozzolanic deposits from Vesuvius' volcano were found [5].

Pozzolanic materials can be classified as natural and artificial pozzolans. Natural pozzolans could be considered the first cementitious materials used for the production of artificial stones, ancient mortars, and concretes, 3000 years ago [6]. Natural pozzolans may be further subdivided into two main groups: (i) those derived from volcanic rocks (volcanic scorias, pumices, etc.); (ii) others derived from rocks and earths [7]. An overview on the use of volcanic scoria as cement replacement can be found in the paper recently published by the author [8]. Although there are numerous works on using natural pozzolan as a substitute for cement, few studies investigating on volcanic scoria have been reported in the literature. 
Many new prediction methods were developed in the last decades to investigate the compressive strength and durability of concrete containing supplementary cementitious materials (SCMs). However, there is no prediction model for concretes containing volcanic scoria as cement replacement. Some previous efforts to develop a predictive model for VS-based concrete used statistical methods that did not seem sufficient for different compositions of concrete. The objective of this work is to develop an empirical model to predict the compressive strength, porosity, and water permeability of concrete containing VS as cement replacement using ANNs. This prediction could be considered useful for concrete mix designers. For this purpose, twenty-one concrete mixes have been prepared with seven replacement levels and three different $w / b$ ratios. Multiple linear regression (MLR) analysis has been used for comparison. In addition, some relationships among the investigated concrete properties have been established. Some estimation equations have been derived, as well.

The importance of this paper is to encourage countries having ample sources of scoria to investigate their potential use as cement replacement and thus making a greener concrete. The current paper focusses not only on one aspect but also it deals with both strength and durability of concrete containing VS as cement replacement. Moreover, technical information on the Syrian pozzolan is scarce, and this paper is part of the first comprehensive research that addresses the investigation of Syrian volcanic scoria. Furthermore, the paper might be particularly interesting for the regions where volcanic scoria is abundant, such as Harrat al-Shaam, which covers parts of Syria, Jordan, and KSA. Regions of similar geology may also get benefits from this study.

\section{Background}

2.1. Artificial Neural Networks. Artificial neural networks (ANNs) are algorithms simulating the human neurons. They are forms of artificial intelligence, which attempts to simulate the networks of the nerve cell (neurons) of the biological central nervous system [9]. An artificial neuron, also called a unit or a node, takes several input connections (dendrites in the biological neuron) which are assigned certain weights (analogous to synapses). The unit then computes the sum of the weighted inputs and applies an activation function (analogous to the cell body in the biological neuron). The result of the unit is then passed on using the output connection (axon function) [10].

In the recent year, such intelligent expert systems have been successfully applied in many fields of engineering, among which, they have been extensively used for predicting the compressive strength of blended cement-based concrete [11-27]. It was proved that the ANN-based strength prediction model could be successfully used to predict the strength of concrete for various mix ingredients and at different curing times. Bilim et al. [15] concluded in their study that ANNs can be an alternative approach for predicting compressive strength of ground-granulated blast furnace slag(GGBFS-) based concrete. Saridemir [16] has established ANN models for predicting the compressive strength of concretes containing metakaolin and silica fume developed up to 180 days of curing. The results have shown that ANNs have a great ability for predicting the compressive strength of metakaolin and silica fume-based concretes. Udhayakumar et al. [17] concluded also that a neural network-based strength model could be used successfully to find out the strength development of fly ash-based concrete with the curing time. Chithra et al. [18] have carried out a comparative study between ANN and MLR for predicting the compressive strength of concretes containing nanosilica and copper slag. The results have revealed that, in terms of the regression coefficient $R^{2}$ and MSE, ANN models have provided better results than MLR. Other studies have used ANNs for predicting some durability-related properties of concrete [2835]. They concluded that ANN models could be used effectively in predicting the concrete durability properties.

ANNs are able to model nonlinear relations between a set of inputs and corresponding outputs. The data set used to develop the ANN models are divided into subsets (i.e., training set, testing set, and validation set). The present paper deals with the prediction of the compressive strength, water permeability, and porosity of concrete using ANNs. MLR analysis has been used for comparison. The predicted concrete properties have been plotted versus the experimental results obtained in the laboratory.

The neural network uses the backpropagation (BP) procedure. The backpropagation learning algorithm, designed to train a feed-forward network, is an effective learning technique used to exploit the regularities and exceptions in the training sample $[36,37]$. Backpropagation neural network (BPNN) which will be used in this research can be considered the most fundamental and widely used method among the ANN methods. It generally consists of multiple layers: an input layer, one or more hidden layers, and an output layer Hidden layers may contain a large number of hidden neurons (processing units). Activation propagation is forwarded from the input layer toward the output layer, and then the algorithm compares the network outputs with known targets as it is a supervised learning algorithm and propagates the error backward. Weights and biases are updated based on calculated errors in order to meet the target.

The most common activation function is the sigmoid function, which is a continuously differentiable function that satisfies the relation, as follows [9]:

$$
f\left(\alpha_{\mathrm{i}}\right)=\frac{1}{1+\exp (-a i)},
$$

where $\alpha$ is a constant used to control the slope of the semilinear region [16].

The activation function is applied to bind the network input and output of the different layers to a specific range that the network can efficiently handle. The logistic sigmoid activation function with a scaling range between 0 and 1 was found to be the best settings for the present application.

By repeating the procedure described above until the error is acceptably small or no marked improvement is noted, the final output can be obtained [38].

2.2. Multiple Linear Regression. Multiple linear regression (MLR) is a statistical method whose general purpose is to 
generate relationship between several independent variables and a dependent variable [39]. In MLR, the predicted value of a single dependent variable $Y$ is a linear transformation of one or more independent variables $X$ such that the sum of squared deviations of the observed and predicted $Y$ is a minimum. With five independent variables, as in the present paper, the prediction of $Y$ is expressed by the following formula:

$$
Y=b_{0}+b_{1} X_{1}+b_{2} X_{2}+b_{3} X_{3}+b_{4} X_{4}+b_{5} X_{5},
$$

where $b_{i}$ values are called regression weights and are calculated in a way that minimizes the sum of squared deviations and $X_{i}$ are the independent variables.

\section{Materials and Methods}

3.1. Experimental Part. Twenty-one concrete mixtures have been prepared using VS-based cements of seven replacement levels $(0,10,15,20,25,30$, and $35 \%)$ and three $\mathrm{w} / \mathrm{b}$ ratios of $0.5,0.6$, and 0.7 . The volcanic scoria was quarried from southeast of Damascus (Figure 1). The investigated properties (i.e., compressive strength, water permeability, and concrete porosity) were obtained after five curing ages (i.e., 2, 7, 28, 90, and 180 days). The compression test was conducted on $150 \mathrm{~mm}$ cubic concrete specimens (Figures 2(a) and 2(b)) in accordance with ISO 4012. Water permeability measured in terms of depth of water penetration was carried out as per standard EN 12390-8 (Figure 2(c)). Porosity measurements were conducted using the vacuum saturation method in accordance with RILEM CPC 11.3 [40]. Table 1 and Figure 3 summarize the chemical composition of the materials used in the concrete mix and the aggregate grading with their physical properties. All of the experimental results were employed in the prediction process using ANNs.

3.2. Network Architecture. Artificial neural network is a powerful data-modeling tool that is able to capture and represent complex input and output relationships. The design of the ANN model requires identifying the network architecture (i.e., number of input neurons, output neurons, hidden layers, and neurons in each hidden layers) and the network settings (activation function and learning rate). Artificial neural networks consist of at least three layers, i.e., an input layer, one or more hidden layer/layers, and an output layer. Three ANN models have been established: ANN1 for predicting the concrete compressive strength, ANN2 for predicting the concrete water permeability, and ANN3 for predicting the concrete porosity. The adopted network architecture consists of the following:

(i) Five neurons $\left(N_{\mathrm{i}}=5\right)$ in the input layer, which represent the variables of cement content (CC: $\mathrm{kg}$ ), volcanic scoria content (VC; $\mathrm{kg}$ ), water content (W; $\mathrm{kg}$ ), superplasticizer content (SP; $\mathrm{kg}$ ), and curing time ( $t$; day)

(ii) One neuron in the output layer, which represents the value of the corresponding compressive strength $(\mathrm{MPa})$, water permeability $(\mathrm{mm})$, or concrete porosity (\%). (iii) One hidden layer with 16 or 15 neurons in ANN1 and ANN3 models, respectively, and two hidden layers with 9 and 7 neurons in the ANN2 model.

Determining the optimum number of the hidden layer neurons is an important issue in order to predict accurately a characteristic using ANNs. The choice of one or two hidden layers is a common practice because of the ability of these networks to approximate any nonlinear function and map any unknown relationships between the input and output variables. Four-layer ANNs (i.e., two hidden layers) have superior fitting capabilities over three-layer ANNs (i.e., one hidden layer); however, three-layer ANNs are computationally faster and have better generalization capabilities $[41,42]$. That is why three- or four-layer ANNs were selected for the present application.

No reasonable theory on how many hidden layer neurons need to be employed for a particular problem has been established. Thus, the best approach to find the optimum number of hidden neurons is to start with a fewer number of neurons and then slightly increase the number of neurons. In the current work, the network models were developed as follows:

(i) ANN1 was built for predicting the compressive strength. The number of hidden neurons that was selected is $16(\sim 3 \mathrm{Ni})[43]$ in one hidden layer. The learning rate and momentum were 0.6 and 0.3 , respectively. This selection was made upon experimenting all the possibilities of increasing hidden neurons from 10 to 22 , learning rate from 0.1 to 0.9 , and momentum from 0.1 to 0.9 for each. The experimental data sets are 525,314 , and 316 samples for compressive strength, water permeability, and concrete porosity, respectively.

(ii) ANN2 was built for predicting the concrete water permeability. The number of hidden neurons that was selected is 9 in the first hidden layer and 7 in the second layer. The learning rate and momentum were 0.5 and 0.9 , respectively. This selection was made upon experimenting all the possibilities of increasing hidden neurons from 7 to 30 in one hidden layer, learning rate from 0.1 to 0.9 , and momentum from 0.1 to 0.9 for each. The experimental data set is 314 samples.

(iii) ANN3 was built for predicting the concrete porosity. The number of hidden neurons that was selected is $15(=3 \mathrm{Ni})$ in one hidden layer. The learning rate and momentum were 0.3 and 0.4 , respectively. This selection was made upon experimenting all the possibilities of increasing hidden neurons from 7 to 22 , learning rate from 0.1 to 0.9 , and momentum from 0.1 to 0.9 for each. The experimental data set is 316 samples.

The architecture of the ANN models is shown in Figures 4-6. Levenberg-Marquardt backpropagation was used as a training function and hyperbolic tangent sigmoid was used as a transfer function. The learning rate, which identifies the amount of adjustments to connection weights 


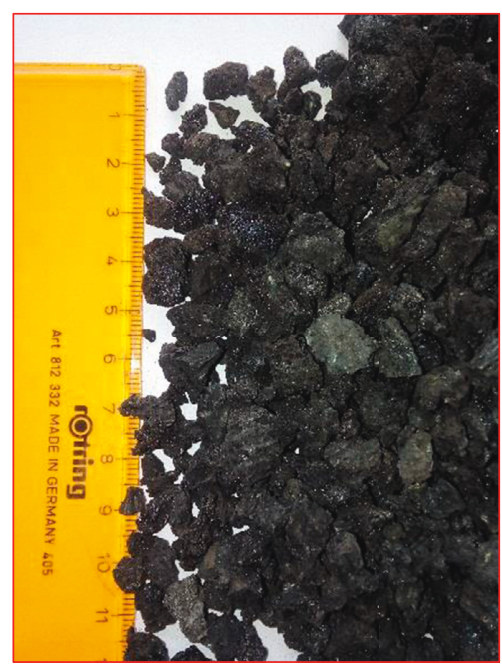

(a)

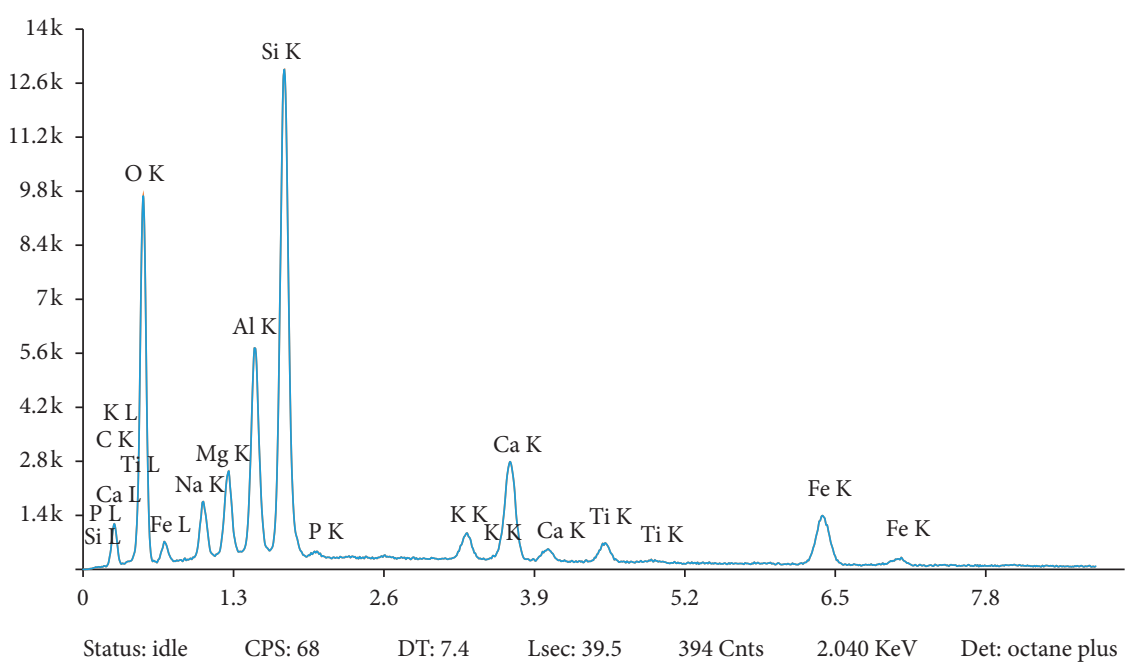

(b)

Figure 1: Macrograph of (a) the investigated volcanic scoria and (b) the EDX analysis.

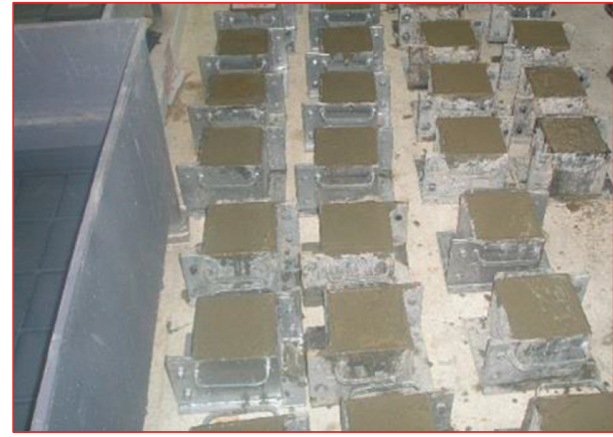

(a)

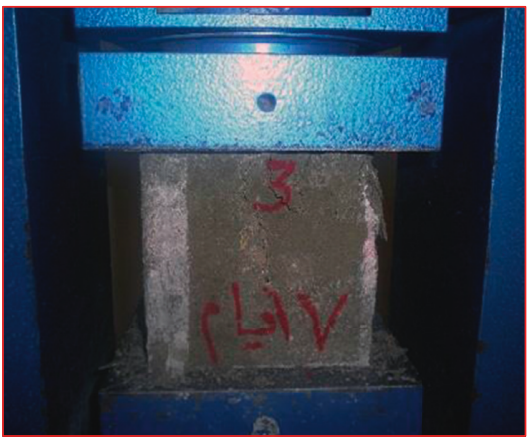

(b)

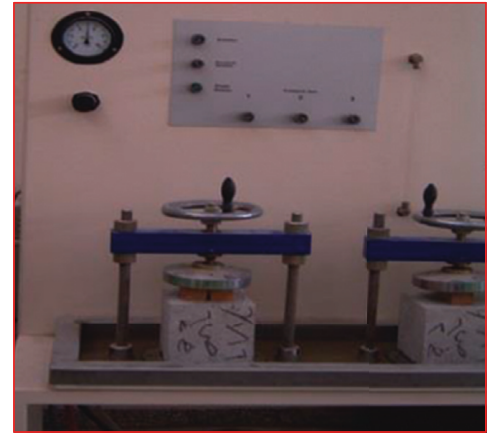

(c)

Figure 2: Photos of (a) the cubic concrete specimens, (b) the compression test, and (c) the water permeability set-up.

TABle 1: Chemical composition of the ingredients used in the concrete mix.

\begin{tabular}{|c|c|c|c|c|c|}
\hline \multirow{2}{*}{ Chemical composition (mass, \%) } & \multicolumn{5}{|c|}{ Materials } \\
\hline & VS & Clinker & Gypsum & Dolomitic aggregate & Natural sand \\
\hline $\mathrm{SiO}_{2}$ & 46.52 & 21.30 & 0.90 & 0.42 & 93.39 \\
\hline $\mathrm{Al}_{2} \mathrm{O}_{3}$ & 13.00 & 4.84 & 0.07 & 0.38 & 0.57 \\
\hline $\mathrm{Fe}_{2} \mathrm{O}_{3}$ & 11.40 & 3.99 & 0.10 & 0.10 & 0.24 \\
\hline $\mathrm{CaO}$ & 10.10 & 65.05 & 32.23 & 31.40 & 1.70 \\
\hline $\mathrm{CaO}_{\mathrm{f}}$ & - & 2.1 & - & - & - \\
\hline $\mathrm{MgO}$ & 9.11 & 1.81 & 0.20 & 20.46 & 0.20 \\
\hline $\mathrm{SO}_{3}$ & 0.27 & 0.25 & 45.29 & 0.18 & 1.15 \\
\hline Loss on ignition & 2.58 & - & 21.15 & 46.48 & 2.52 \\
\hline $\mathrm{Na}_{2} \mathrm{O}$ & 2.14 & 0.60 & - & 0.06 & 0.06 \\
\hline $\mathrm{K}_{2} \mathrm{O}$ & 0.77 & 0.28 & - & 0.30 & 0.05 \\
\hline $\mathrm{Cl}^{-}$ & $<0.1$ & 0.05 & - & 0.021 & 0.017 \\
\hline
\end{tabular}

during training, was determined based on the network performance. The learning rate and momentum were adjusted for each ANN to get the best performance. The data set was divided into three subsets as follows: $70 \%$ for training, $15 \%$ for testing, and $15 \%$ for validating. The correlation coefficient $(R)$ obtained for training, testing, validating, and overall data for each ANN are shown in Table 2.

The artificial neural networks have been established using MATLAB software, Neural Network Toolbox. The 


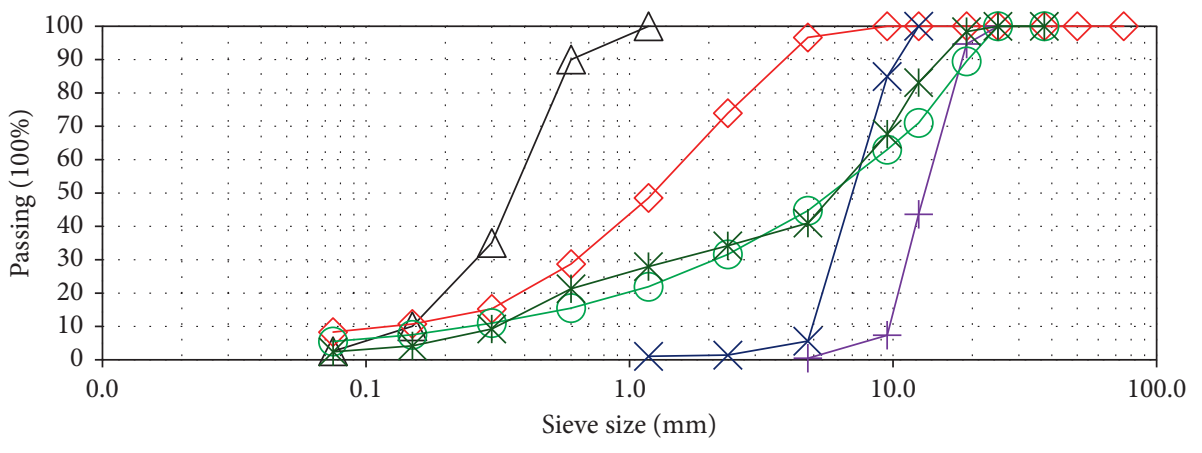

$$
\begin{aligned}
& \triangle \text { Natural river sand }(\mathrm{SG}=2.69 \text {; absorption }(\%)=1.60) \\
& \diamond \text { Crushed sand }(\mathrm{SG}=2.80 \text {; absorption }(\%)=1.57) \\
& \star \quad \text { Crushed medium-size aggregate }(\mathrm{SG}=2.83 \text {; absorption }(\%)=1.3 \text {; Los Angeles Nr. }=20.5) \\
& \mp \text { Crushed coarse aggregate }(\mathrm{SG}=2.83 \text {; absorption }(\%)=1.30 ; \text { Los Angeles Nr. = 20.5) } \\
& \odot \text { Fuller curve } \\
& * \quad \text { Job mix }
\end{aligned}
$$

Figure 3: Particle-size distribution of the aggregates with some physical properties.

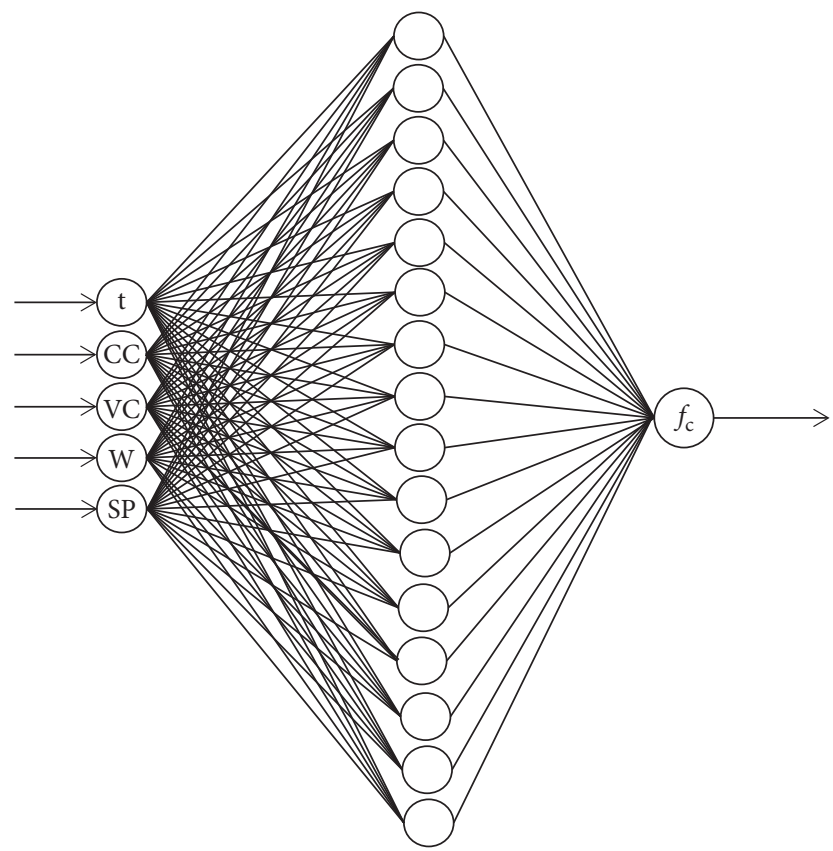

FIgURE 4: ANN1 model for predicting the compressive strength of VS-based concrete.

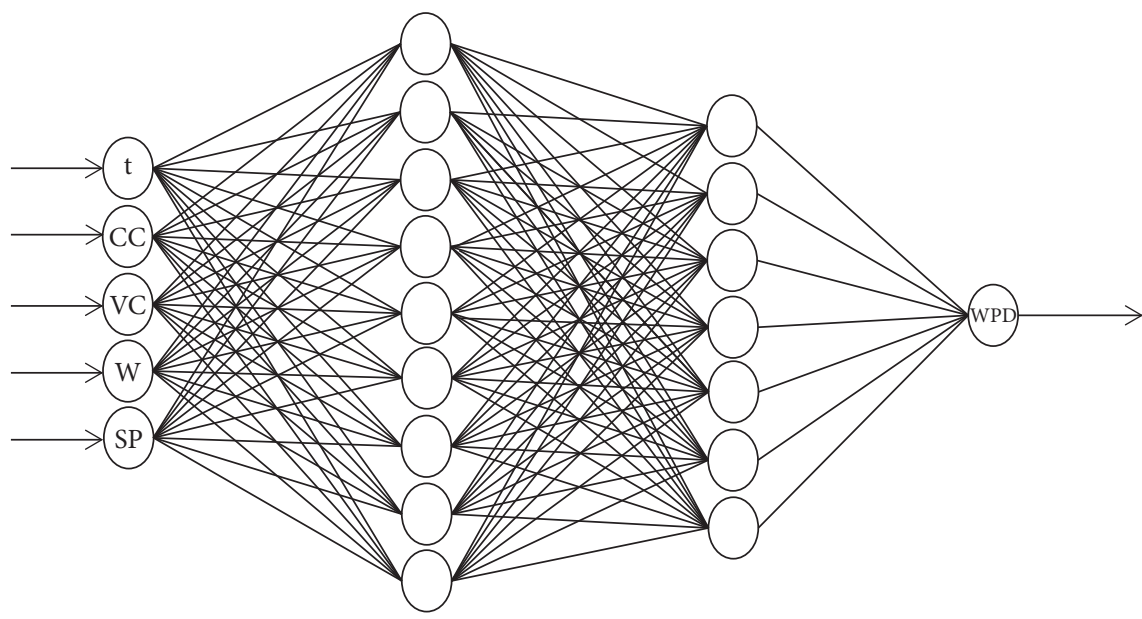

FIGURE 5: ANN2 model for predicting the water permeability of VS-based concrete. 


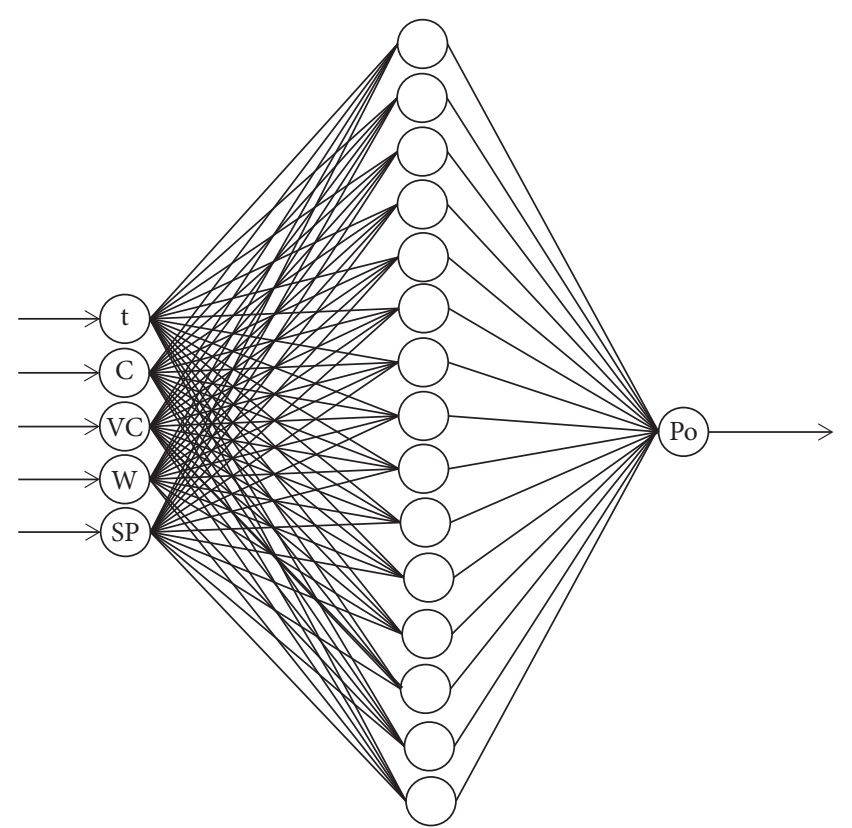

FIGURE 6: ANN3 model for predicting the porosity of VS-based concrete.

TABle 2: Correlation coefficients $(R)$ of artificial neural network models.

\begin{tabular}{lcccc}
\hline \multirow{2}{*}{ ANN model } & \multicolumn{4}{c}{ Correlation coefficient $(R)$} \\
& Training & Testing & Validating & $\begin{array}{c}\text { Overall } \\
\text { data }\end{array}$ \\
\hline $\begin{array}{l}\text { ANN1 (compressive } \\
\text { strength) }\end{array}$ & 0.99976 & 0.99937 & 0.99953 & 0.99968 \\
$\begin{array}{l}\text { ANN2 (water } \\
\text { permeability) }\end{array}$ & 0.99927 & 0.99732 & 0.99864 & 0.99891 \\
ANN3 (porosity) & 0.99972 & 0.99951 & 0.99873 & 0.99954 \\
\hline
\end{tabular}

regression analysis has also been carried out using MATLAB software.

The validity of the constructed models was evaluated using the following criteria:

(i) Root mean squared error (RMSE): the error that arose during the training, testing, and validating in ANN models can be evaluated by the RMSE, which can be calculated using the following function:

RMSE $=\sqrt{\frac{1}{n} \sum_{i=1}^{n}(\text { experimental value }- \text { predicted value })^{2}}$.

(ii) The RMSE is used in evaluating the average vertical distance between the data points and the corresponding points on the fitting straight. When the RMSE value is smaller, the ANN model is better.

(iii) Mean absolute percentage error (MAPE): the average of the absolute percentage error can be calculated using the following function:

$$
\operatorname{MAPE}=\left(\frac{1}{n} \sum_{i=1}^{n}\left|\frac{\text { experimental value }- \text { predicted value }}{\text { experimental value }}\right|\right) \times 100 \% .
$$

(iv) R-square coefficient $\left(R^{2}\right)$ : the R-square coefficient is the absolute fraction of variance of a model. $R^{2}$ can be calculated using the following function:

$$
R^{2}=1-\frac{\text { sum of squares of residuals }}{\text { sum of squares of predicted values }} \text {. }
$$

When $R^{2}$ is closer to 1 , this means, there is a closer relationship between output and targeted output.

(v) Durbin-Watson statistic (DW): this statistic criterion is used to verify the existence of multicollinearity. It varies between 0 and 4 . The acceptable range of 1.5 to 2.5 indicates that the established models are unaffected by problems related to multicollinearity.

\section{Results and Discussion}

4.1. Compressive Strength Development. Results of the compressive strength development test are plotted in Figures 7-9. As expected, all concretes showed an increase in strength with curing time. Concretes specimens containing VSO had higher compressive strengths at any curing time compared to VS-based binder concretes. In addition, the compressive strength of VS-based concretes decreased with the volcanic scoria replacement level for all curing times. This could be explained by (i) the reduction of cement content in the mix with the increase of VS content; i.e., the dilution effect and (ii) the slowness of the pozzolanic reaction [40]. However, due to the continuation of this reaction and the formation of a secondary C-S-H, a greater degree of hydration was achieved resulting in strengths after 90 and 180 days which were comparable to those of VS0-based specimens [40]. Furthermore, the compressive strength decreased significantly with the increase in $\mathrm{w} / \mathrm{b}$ ratio.

4.2. Water Permeability and Concrete Porosity. Results of water penetration depth and porosity tests are illustrated in Figures 10 and 11, respectively, for all binder types, curing age, and w/b ratios. Water penetration depth can be considered as an indication of permeable and impermeable concrete. A depth of less than $50 \mathrm{~mm}$ classifies the concrete as impermeable and a depth of less than $30 \mathrm{~mm}$ as impermeable under aggressive conditions [44]. None of concretes even with $\mathrm{w} / \mathrm{b}=0.5$ was found to be impermeable before 28 days of curing. However, concretes containing VS20 to VS35 can be considered as impermeable after 28 days of curing and as impermeable under aggressive environments after 90 days of curing, according to Neville [44]. In addition, none of concretes with $\mathrm{w} / \mathrm{b}=0.7$ was found to be impermeable under aggressive environments even after 180 days curing. Porosity of all mixes decreased with curing time. Furthermore, porosity of the concretes containing binders with high 


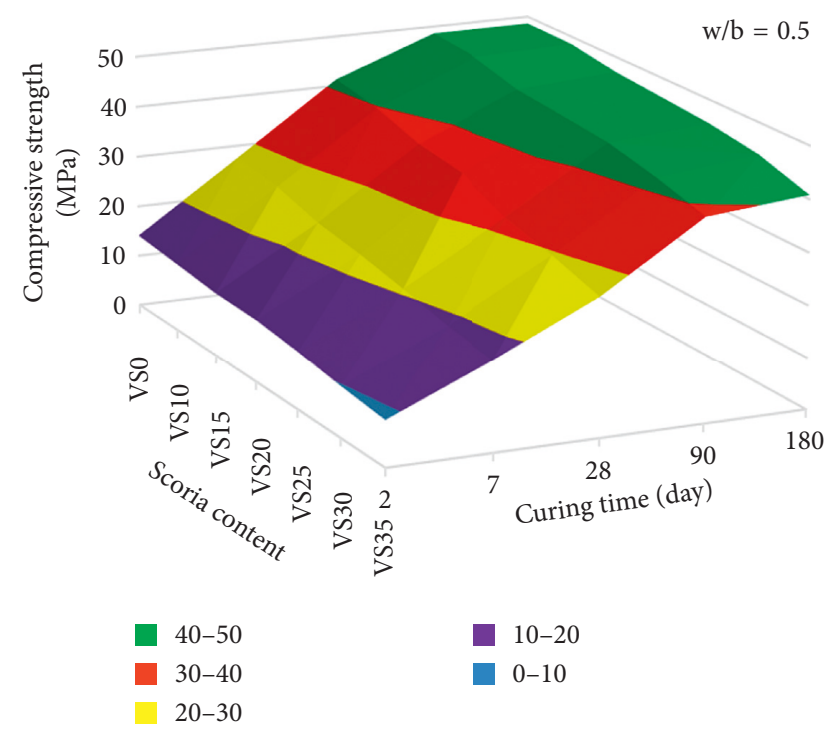

FIGURE 7: Development of compressive strength of VS-based binder concretes with curing ages at $w / b=0.5$.

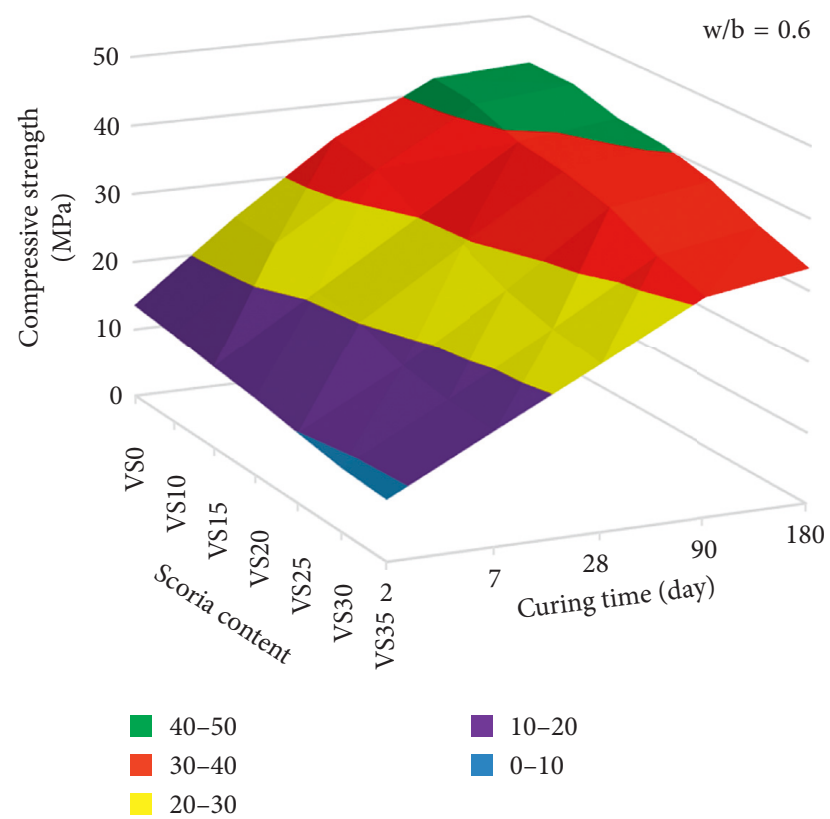

FIGURE 8: Development of compressive strength of VS-based binder concretes with curing ages at $\mathrm{w} / \mathrm{b}=0.6$.

replacement levels of VS demonstrated much lower porosity as compared to the VSO-based concrete.

The reduction in the water permeability and porosity could be attributed to the pozzolanic reaction between the glassy phase in volcanic scoria and the $\mathrm{CH}$ liberated from hydration of C3S and C2S [40]. This was also confirmed by the SEM and EDX analysis.

4.3. Correlations between Compressive Strength and Permeability-Related Properties. Some correlations between compressive strength and each of water permeability and porosity of the investigated concretes are plotted in

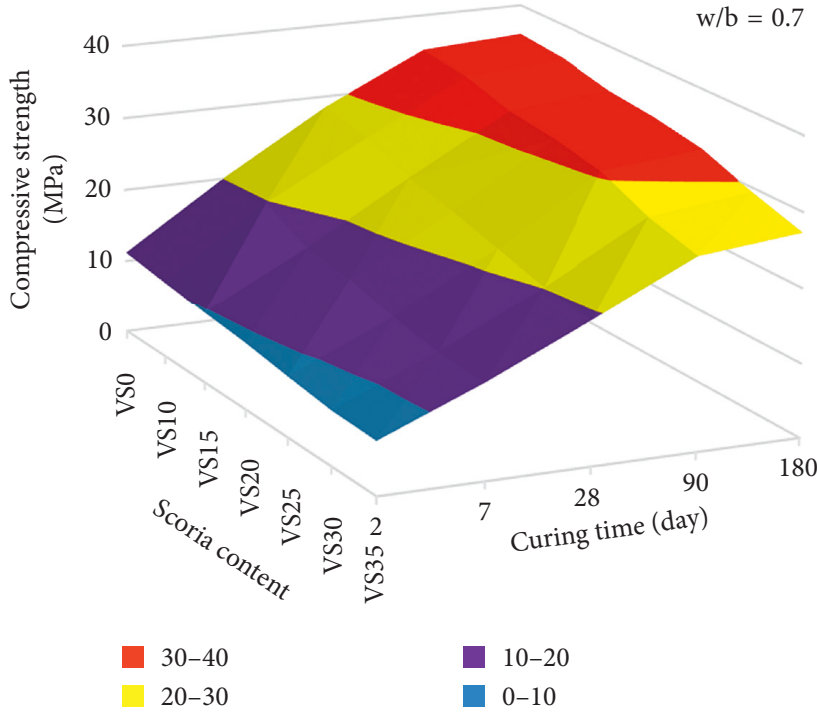

FIgURE 9: Development of compressive strength of VS-based binder concretes with curing ages at $\mathrm{w} / \mathrm{b}=0.7$.

Figures 12 and 13. These correlations were calculated for the entire population of test results. As shown in Figures 12 and 13 , there are no reasonable relationships between the compressive strength and each of permeability-related properties of VS-based binder concrete. This supports the fact that strong concrete does not always ensure durable concrete. For instance, VS25-based binder concrete has lower compressive strengths, but higher water impermeability compared to VSO-based binder concrete at almost all curing times.

4.4. Correlations between Water Permeability and Porosity. The relationship between the water permeability and porosity is given in Figure 14. Definite correlations with a regression coefficient $\left(R^{2}\right)$ of 0.92 were observed between the water permeability and porosity, such that one can be predicted from the knowledge of the other. The correlation between the fitted parameters can be graded excellent when $R^{2} \geq 0.85$ [45]. Such similar relationship may need to be developed for other types of concrete aggregates, different volcanic scoria types, and other curing conditions.

4.5. ANN and MLR Analysis. Figures 4-6 show the structure of ANN models developed to predict the values of compressive strength, water permeability, and porosity of VSbased concrete. The calculated statistical values are tabulated in Table 3. The training has been carried out with $70 \%$ of the samples. RMSE values of $0.3066,1.9783$, and 0.3129 , MAPE values of $1.2106,2.6357$, and 1.4998 , and $R^{2}$ values of 0.9999 , 0.9995 , and 0.9998 were obtained for prediction of the compressive strength, the water permeability, and the concrete porosity, respectively. The testing has been carried out with $15 \%$ of the samples. RMSE values of $0.3931,2.4439$, and 0.4050 , MAPE values of 1.5470, 4.8220, and 2.0528, and $R^{2}$ values of $0.9998,0.9990$, and 0.9997 were obtained for 

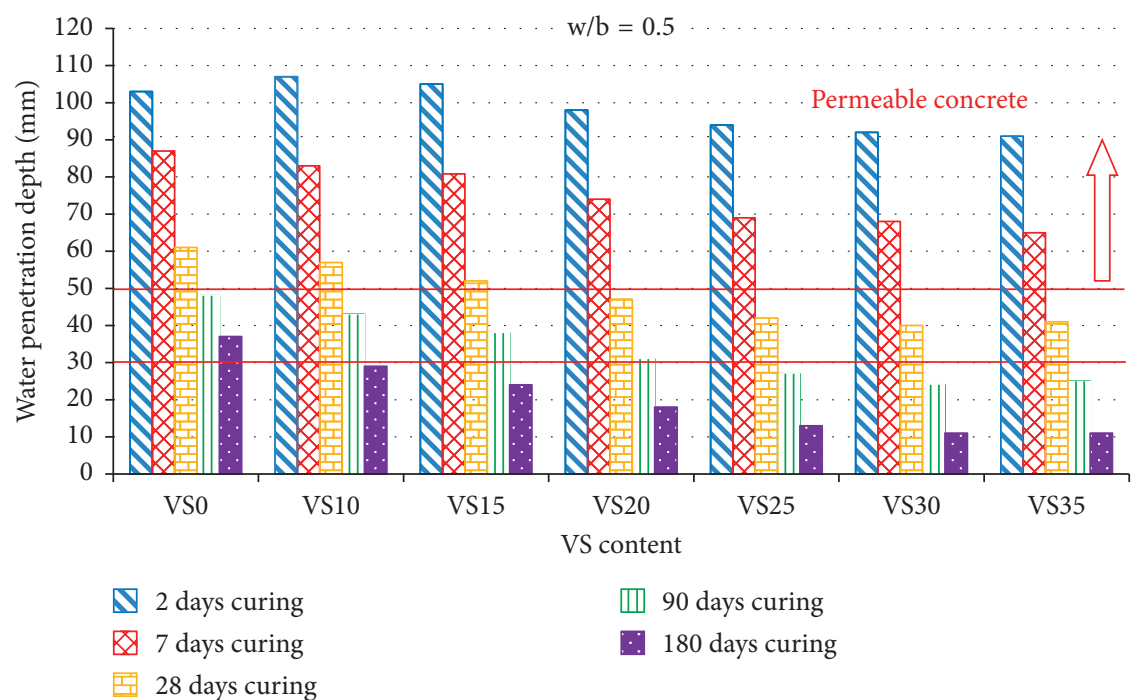

(a)
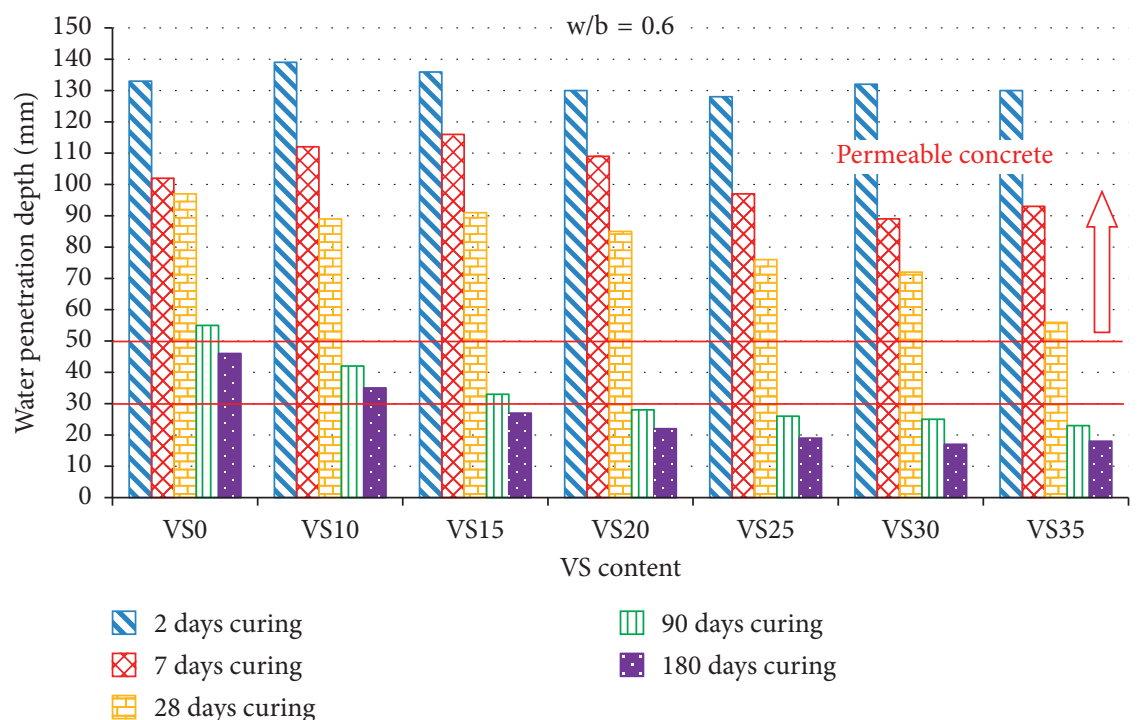

(b)
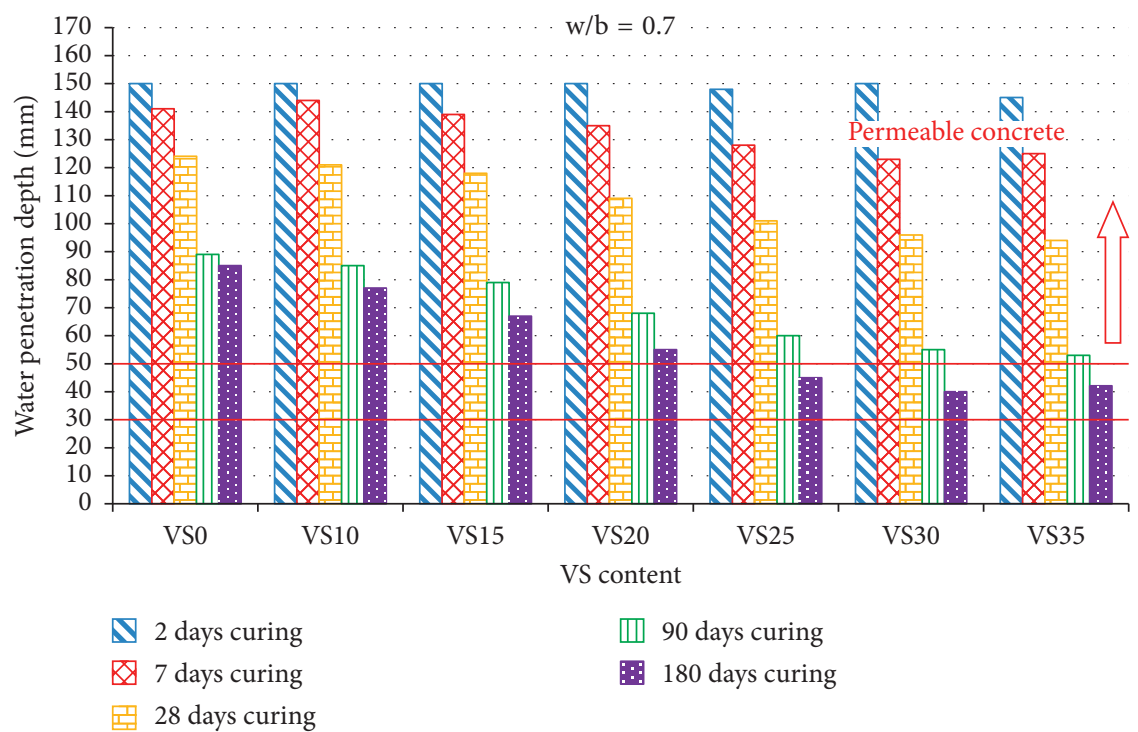

(c)

Figure 10: Water penetration depths of VS-based binder concretes of various w/b ratios cured for different times: $(a) w / b=0.5 ;(b) w / b=$ $0.6 ;(c) w / b=0.7$. 


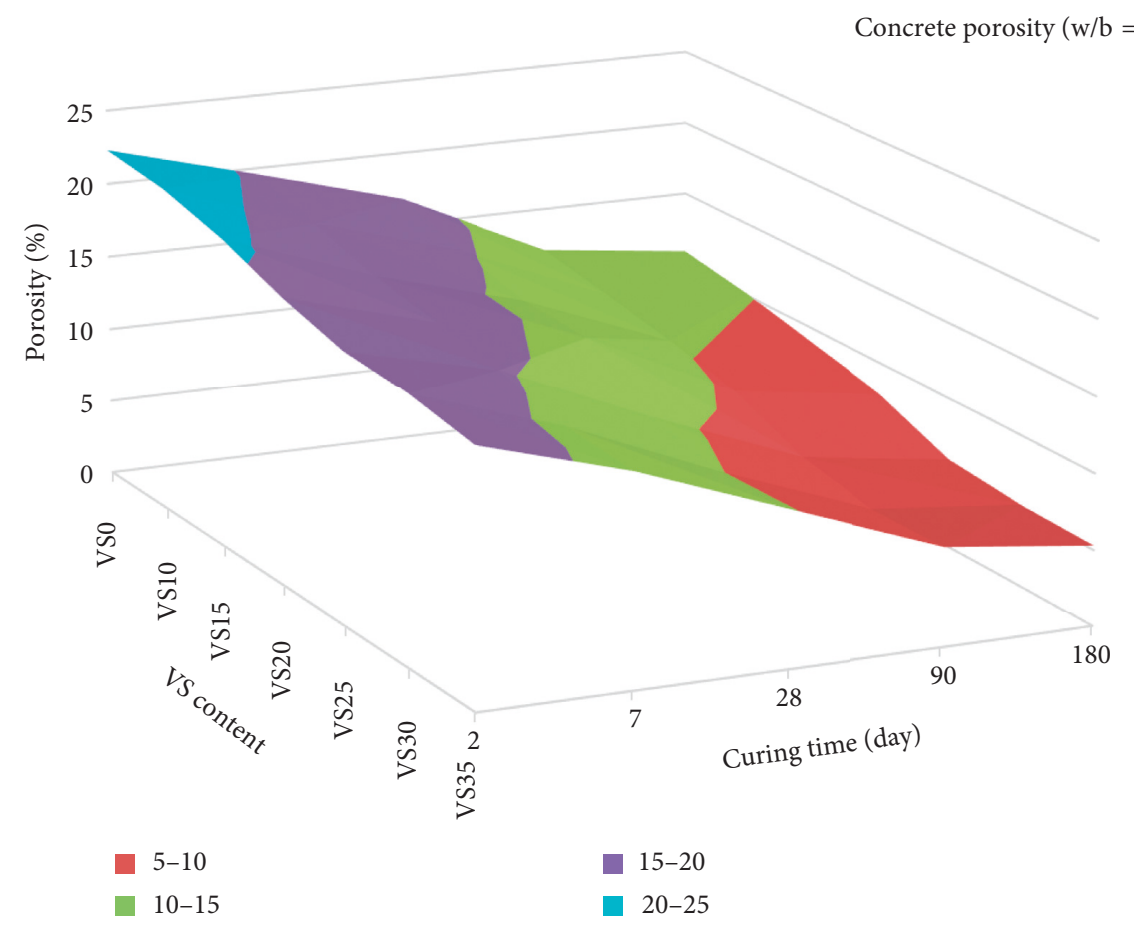

(a)

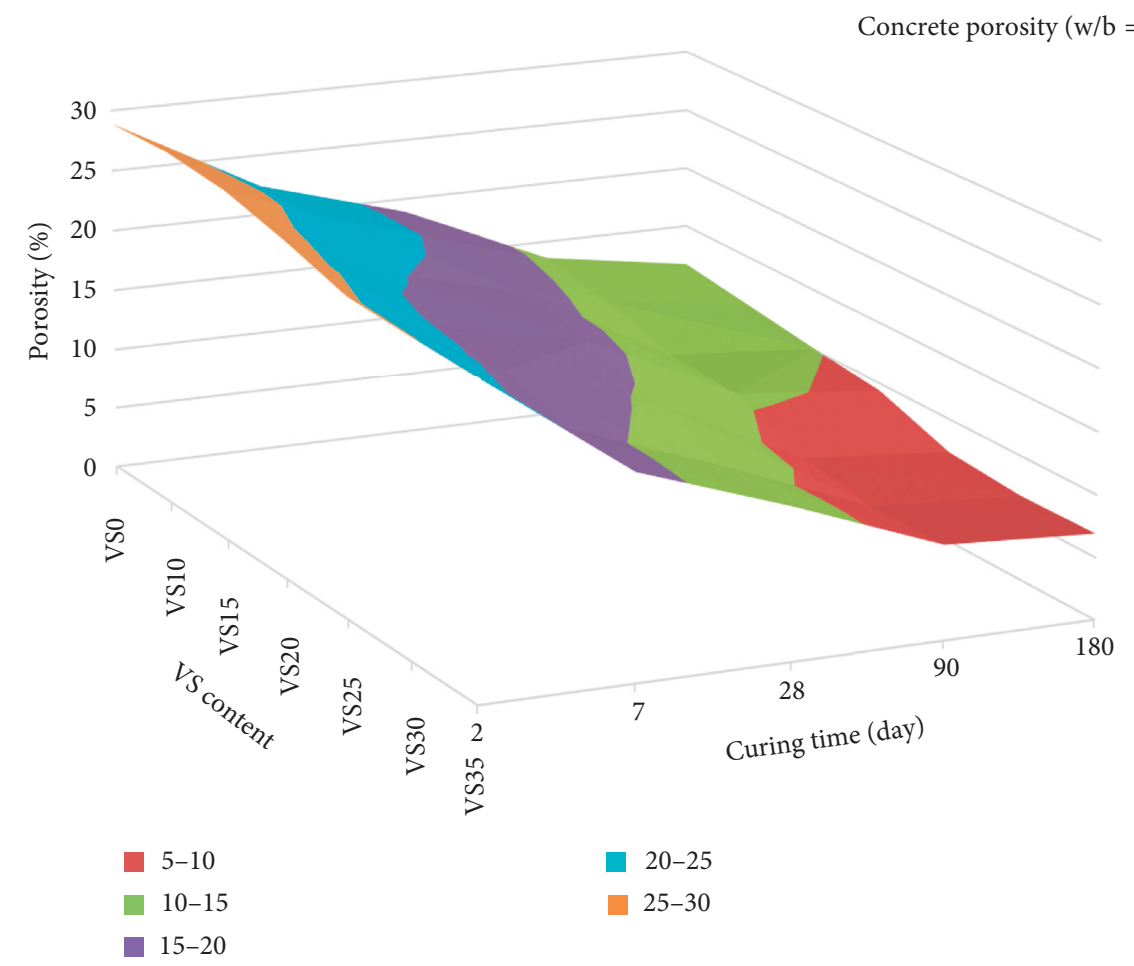

(b)

FIgURE 11: Continued. 


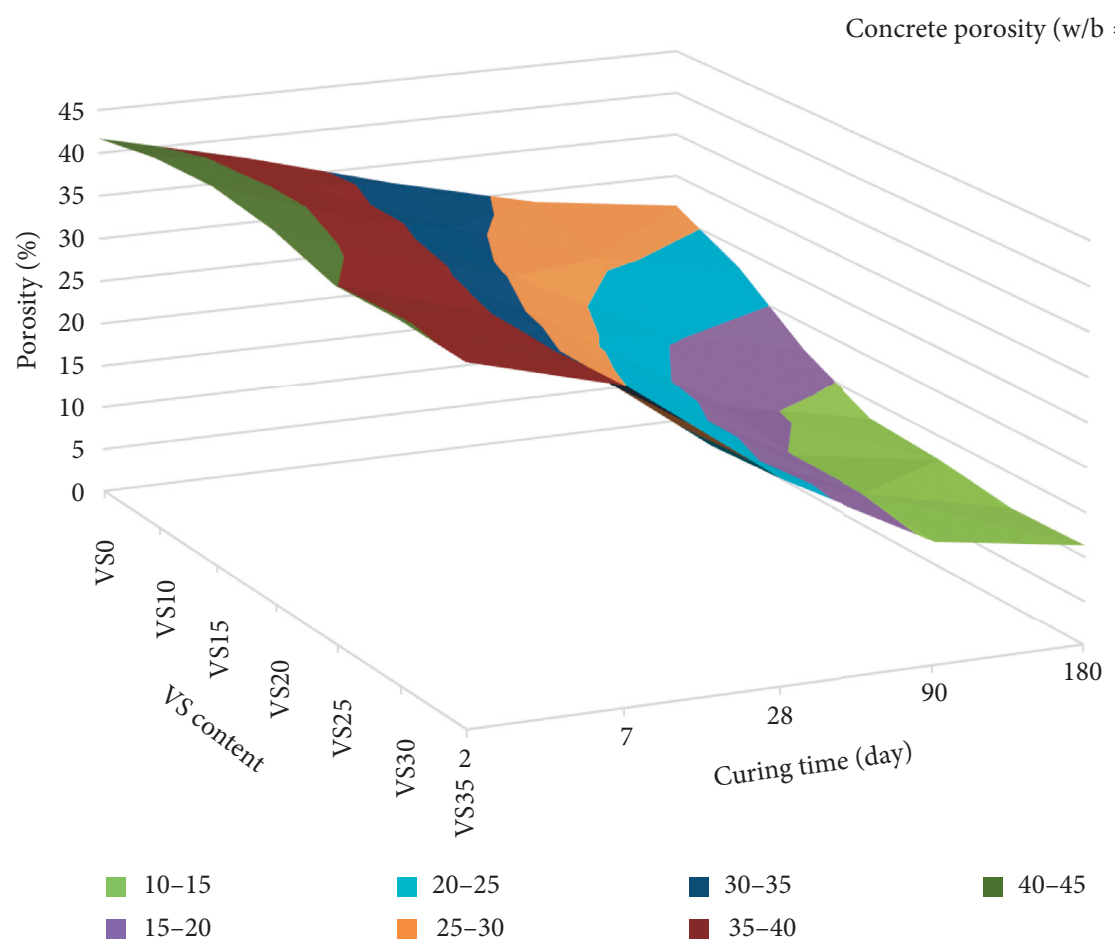

(c)

Figure 11: Porosity values of VS-based binder concretes of various $w / b$ ratios cured for different times: (a) w/b $=0.5 ;(b) w / b=0.6 ;(c) w / b=0.7$.

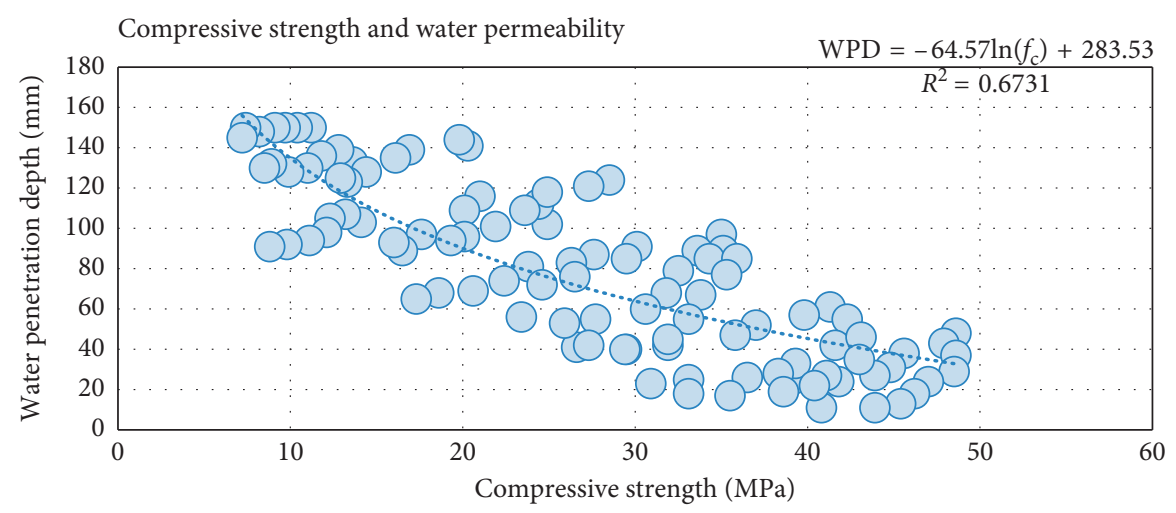

FIGURE 12: Correlation between water permeability and compressive strength of VS-based concretes.

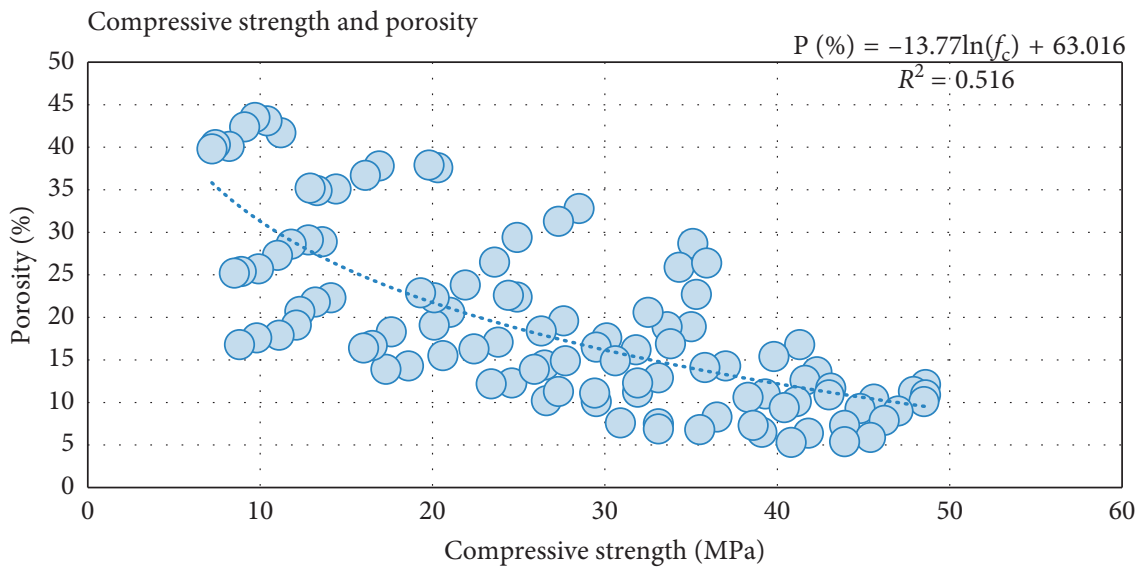

FIGURE 13: Correlation between porosity and compressive strength of VS-based concretes. 


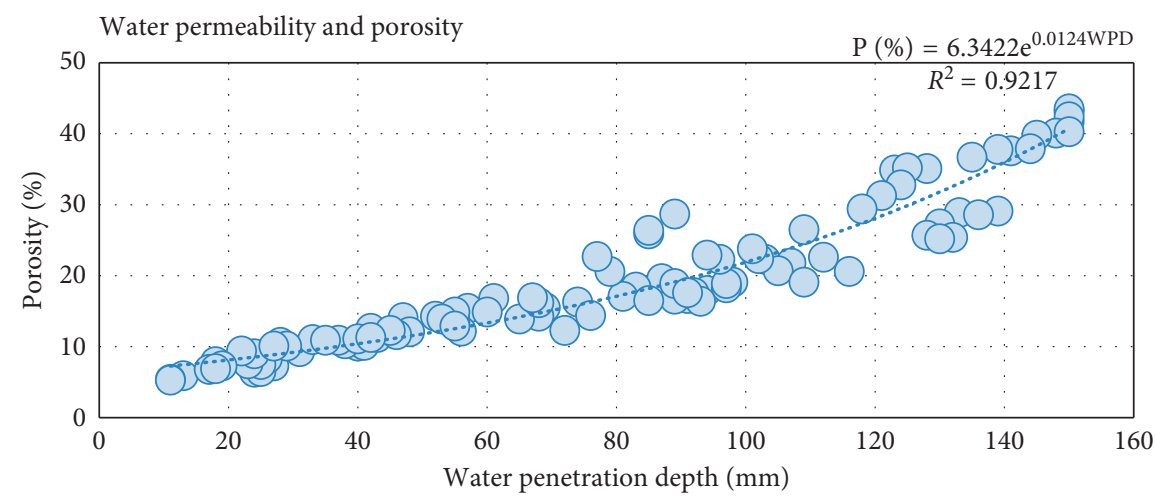

FIGURE 14: Correlation between water permeability and porosity of VS-based concretes.

TABLE 3: Results obtained for ANN models.

\begin{tabular}{|c|c|c|c|c|c|c|c|c|c|c|c|c|}
\hline \multirow{2}{*}{ Model } & \multicolumn{4}{|c|}{ Training } & \multicolumn{4}{|c|}{ Testing } & \multicolumn{4}{|c|}{ Validating } \\
\hline & $R^{2}$ & RMSE & MAPE & DW & $R^{2}$ & RMSE & MAPE & DW & $R^{2}$ & RMSE & MAPE & DW \\
\hline ANN1 & 0.9999 & 0.3066 & 1.2106 & 1.7605 & 0.9998 & 0.3931 & 1.5470 & 1.9505 & 0.9998 & 0.3899 & 1.7307 & 1.6328 \\
\hline ANN2 & 0.9995 & 1.9783 & 2.6357 & 1.7003 & 0.9990 & 2.4439 & 4.8220 & 1.8094 & 0.9981 & 4.3322 & 4.7976 & 1.7467 \\
\hline ANN3 & 0.9998 & 0.3129 & 1.4998 & 1.5035 & 0.9997 & 0.4050 & 2.0528 & 1.9018 & 0.9995 & 0.4859 & 2.6921 & 1.6489 \\
\hline
\end{tabular}

ANN1: compressive strength; ANN2: water permeability; ANN3: concrete porosity.

prediction of the compressive strength, the water permeability, and the concrete porosity, respectively. The validation has been carried out with also $15 \%$ of the samples. RMSE values of $0.3899,4.3322$, and 0.4859 and $R^{2}$ values of $0.9998,0.9981$, and 0.9995 were obtained for prediction of the compressive strength, the water permeability, and the concrete porosity, respectively. The results mentioned above show that training has given the best performance by providing a very low MSE and $R^{2}$ value very close to one. Furthermore, testing and validation have given an excellent performance by providing a very low RMSE and $R^{2}$ value approximately equal to one. In contrast to the ANN results (Table 4), RMSE values of 6.11, 4.39, and 17.5, MAPE values of 20.922, 52.3229, and 59.212, and $R^{2}$ values of $0.748,0.82$, and 0.829 were obtained by the MLR analysis for predicting the compressive strength, the water permeability, and concrete porosity, respectively. Furthermore, the obtained DW values for ANN models were between 1.5 and 2.5, consistent with the ideal range of values. However, the MLR models had very low DW values, which ranged from 0.026 to 0.157 . The DW values signify the incidence of null and positive autocorrelation for ANN and MLR models, respectively.

Figures 15-17 clearly show that the goodness-of-fit of the ANN models is superior when compared to the MLR models. In addition, the statistical values shown above demonstrate that the prediction of the compressive strength, water permeability, and porosity of VS-based concrete with ANN models is highly accurate. The results related to compressive strength are in well agreement with those obtained by Chithra et al. [18], Ferhat Bingol et al. [46], and Saridemir [47]. However, as no or very little investigations on the prediction of water permeability and porosity of concretes containing natural pozzolans were found in the literature, the results could be comparable with other
TABLE 4: Results obtained for MLR models.

\begin{tabular}{lccccc}
\hline \multirow{2}{*}{ Models } & \multicolumn{4}{c}{ Evaluation criteria } & Number of data set \\
& $R^{2}$ & DW & RMSE & MAPE & samples \\
\hline MLR1 & 0.748 & 0.0259 & 6.11 & 20.922 & 367 \\
MLR2 & 0.82 & 0.1566 & 4.39 & 52.3229 & 222 \\
MLR3 & 0.829 & 0.1423 & 17.5 & 59.212 & 220 \\
\hline
\end{tabular}

MLR1: compressive strength; MLR2: water permeability; MLR3: concrete porosity.

concrete durability-related properties, such as chloride ion permeability [31] and sulfate attack [30].

Furthermore, it is worth mentioning that the accuracy of ANN models in terms of RMSE, MAPE, $R^{2}$, and DW can be arranged in the following order: compressive strength $\longrightarrow$ concrete porosity $\longrightarrow$ water permeability. The sequence in MLR models is different from that in ANNs and can be written as follows when $R^{2}$ is taken into account: concrete porosity $\longrightarrow$ water permeability $\longrightarrow$ compressive strength and can be written as follows when RMSE and MAPE are taken into account: compressive strength $\longrightarrow$ water permeability $\longrightarrow$ concrete porosity.

The equations obtained by MLR analysis are as follows:

$$
\begin{aligned}
f_{\mathrm{c}}(\mathrm{MPa})= & 0.1311 \times t+0.1631 \times \mathrm{CC}+0.0768 \\
& \times \mathrm{VC}-0.1509 \times \mathrm{W}-0.0164 \times \mathrm{SP}, \\
\mathrm{WPD}(\mathrm{mm})= & -0.4772 \times t-0.2582 \times \mathrm{CC}-0.4815 \\
& \times \mathrm{VC}+0.9757 \times \mathrm{W}+4.7588 \times \mathrm{SP}, \\
\mathrm{Po}(\%)= & -0.0884 \times t-0.292 \times \mathrm{CC}-0.359 \\
& \times \mathrm{VC}+0.5724 \times \mathrm{W}+5.9841 \times \mathrm{SP},
\end{aligned}
$$

where $f_{\mathrm{c}}$ is the compressive strength (MPa), WPD is the water penetration depth $(\mathrm{mm})$, Po is the concrete porosity $(\%), t$ is the curing time (day), CC is the cement content $(\mathrm{kg})$, 


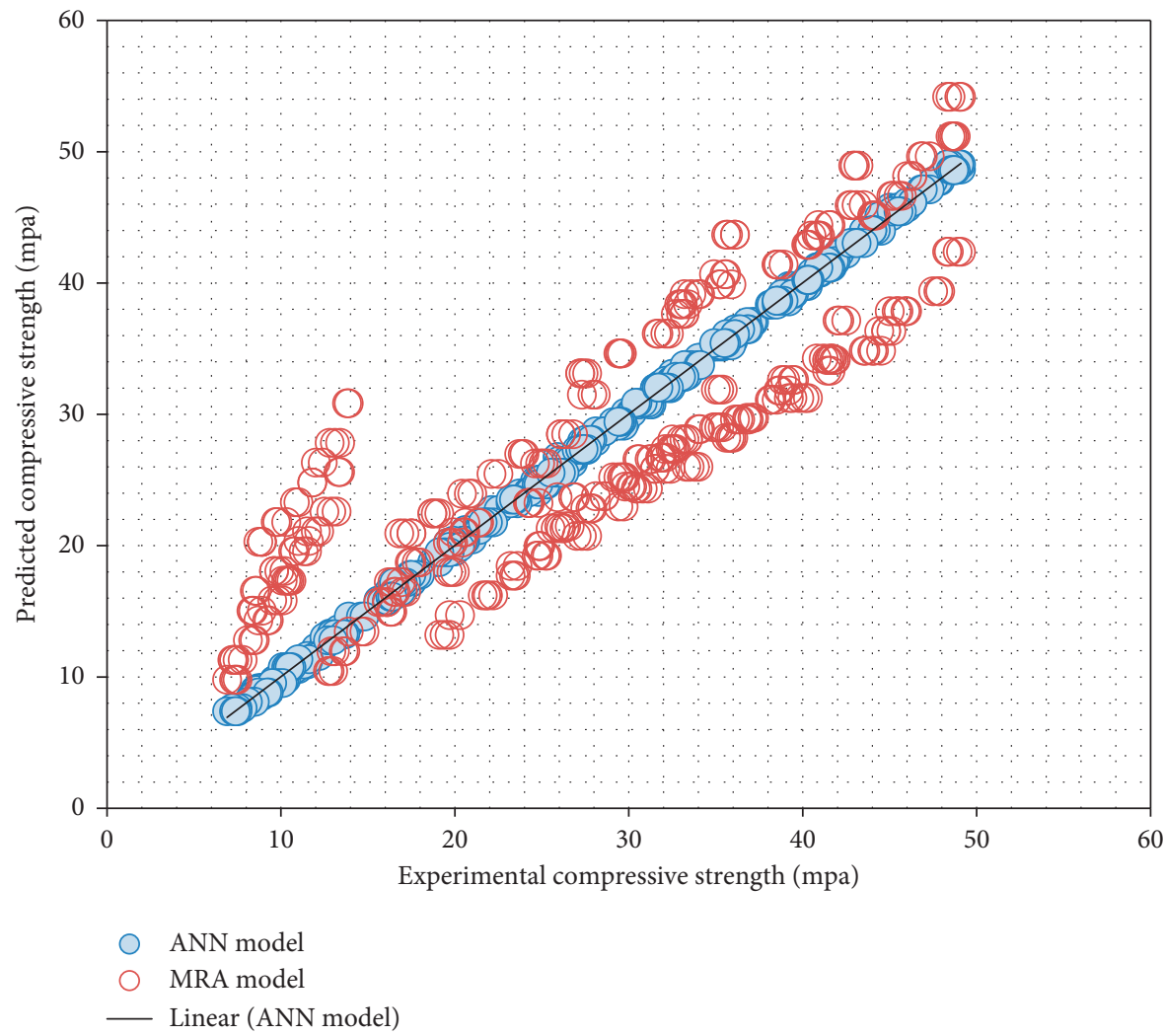

Figure 15: Predicted compressive strength versus experimental compressive strength for models ANN1 and MLR1.

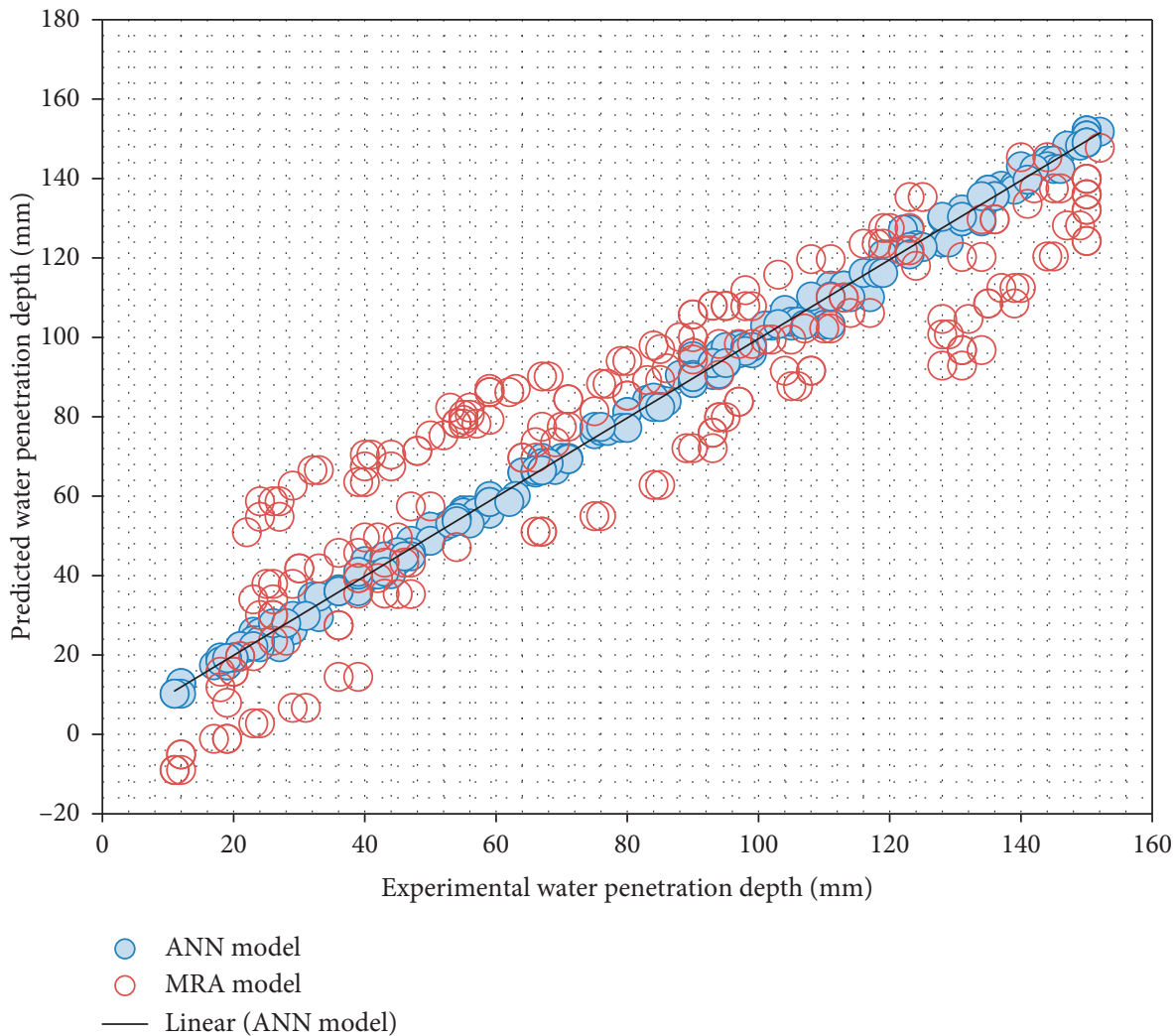

FIGURE 16: Predicted water permeability versus experimental water permeability for models ANN1 and MLR1. 


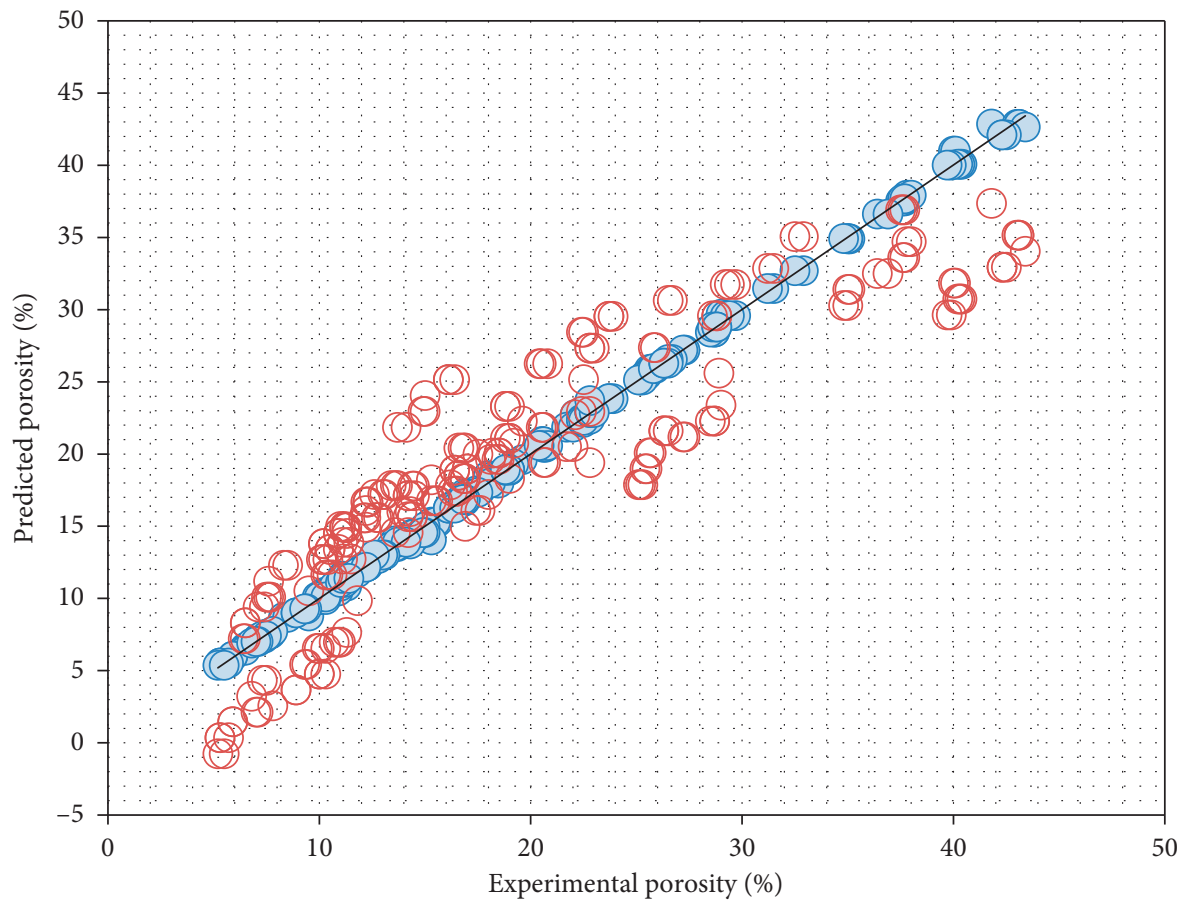

O ANN model

O MRA model

— Linear (ANN model)

FIgURE 17: Predicted concrete porosity versus experimental concrete porosity for models ANN1 and MLR1.

VC is the volcanic scoria content $(\mathrm{kg}), \mathrm{W}$ is the water content, and SP is the superplasticizer content.

4.6. Sensitivity Analysis of ANNModels. In order to assess the relative importance of the input variables, sensitivity analysis was conducted based on the Garson equation [48]. Garson [48] proposed an equation based on the partitioning of connection weights:

$$
I_{j}=\frac{\sum_{m=1}^{m=N h}\left(\left(\left|w_{j m}^{i h}\right| / \sum_{k=1}^{N i}\left|w_{k m}^{i h}\right|\right) \times\left|w_{m n}^{h o}\right|\right)}{\sum_{k=1}^{k=N i}\left\{\sum_{m=1}^{m=N h}\left(\left(\left|w_{k m}^{i h}\right| / \sum_{k=1}^{N i}\left|w_{k m}^{i h}\right|\right) \times\left|w_{m n}^{h o}\right|\right)\right\}},
$$

where $I_{j}$ is the relative importance of the $j$ th input parameter on the output; $N i$ and $N h$ are the numbers of input and hidden neurons, respectively; $w$ is connection weights; the superscripts $i, h$, and $o$ refer to input, hidden, and output layers, respectively; and the subscripts $k, m$, and $n$ refer to input, hidden, and output neurons, respectively.

Table 5 shows the weights between input and hidden layers (W1) and weights between hidden and output layers (W2). Table 6 shows the relative importance of the input parameters (curing time, cement content, VS content, water content, and superplasticizer content). It can be noted that all parameters have a strong effect on the investigated properties.

As clearly seen in Table 5, curing time was found to be the most influential parameter with a relative importance of $32.2 \%, 33.52 \%$, and $51.80 \%$ for compressive strength, concrete porosity, and water permeability, respectively. The higher relative importance of curing time can be attributed to the significant effect of this parameter on the permeability-related properties of concretes containing volcanic scoria as cement replacement. As mentioned earlier, a significant gradual improvement in permeability-related properties can be obtained with an increase in curing time, particularly at ages $\geq$ 28 days [38]. In addition, it is to be noted that other parameters have also considerable effects on the output values, particularly those forming the "w/b" ratio, i.e., cement content, VS content, and water content.

4.7. Microstructural Investigation. Scanning electron micrographs (SEM) of 7 day-, 28 day-, and 90 day-cured VS30based pastes are shown in Figure 18. Figure 18(a) clearly shows a porous and noncompacted structure in seven daycured VS30-based paste. However, a denser structure can be clearly observed after 28 and 90 days of curing (Figures 18(b) and $18(\mathrm{c}))$. This can be attributed to the continuation of the cement hydration, and formation of cementitious phases, such as (C-S-H) and (C-A-S-H) through the pozzolanic reaction between the glassy phase in volcanic scoria and $\mathrm{CH}$ released during the hydration of calcium silicates $\left(\mathrm{C}_{3} \mathrm{~S}\right.$ and $\left.\mathrm{C}_{2} \mathrm{~S}\right)$ [49].

\section{Conclusion}

In this study, artificial neural networks were used for the prediction of $2,7,28,90$, and 180 days compressive strength, 
TABLE 5: Weight matrix and weights between input and hidden layers (W1) and between hidden and output layers (W2) for the ANN1 model.

\begin{tabular}{|c|c|c|c|c|c|c|}
\hline \multirow{3}{*}{ Neuron } & \multicolumn{5}{|c|}{$\mathrm{W} 1$} & \multirow{3}{*}{$\begin{array}{c}\text { W2 } \\
\text { Output }\end{array}$} \\
\hline & & & Input & & & \\
\hline & Time (day) & Cement content $(\mathrm{kg})$ & VS content $(\mathrm{kg})$ & Water content $(\mathrm{kg})$ & SP & \\
\hline 1 & -2.105944022 & 1.075228351 & 1.255199036 & 0.438755839 & -0.030683697 & 1.279718465 \\
\hline 2 & 0.144053427 & -0.972020695 & 0.742996724 & 1.753640631 & -1.340918263 & -1.208902522 \\
\hline 3 & 1.732934016 & 0.61985474 & -1.155641212 & -1.283690471 & 3.243864115 & 0.460723363 \\
\hline 4 & 0.903445767 & 0.372764295 & 1.572839487 & -0.87906307 & 1.904073089 & 0.705296001 \\
\hline 5 & 0.938501968 & -1.091473696 & -2.116933639 & -0.459056052 & 1.573936415 & 1.53887134 \\
\hline 6 & 0.344253977 & -0.597794971 & 0.779210827 & 1.235683476 & 2.059459437 & 0.961634634 \\
\hline 7 & -1.024890536 & -1.466697926 & -1.591821924 & -1.081779779 & 1.829483202 & 0.698867474 \\
\hline 8 & -0.064928174 & -1.591852569 & 1.716382139 & 1.62579402 & -2.437814145 & -0.331804241 \\
\hline 9 & -1.498209432 & 0.875620108 & -0.423664145 & -1.895854904 & 2.039710262 & 0.545700344 \\
\hline 10 & -0.233072918 & -1.362387421 & 1.333842112 & -1.465558 & 1.098041189 & -0.562090401 \\
\hline 11 & -0.936088182 & 2.726784678 & -1.120598625 & -2.150579249 & -0.530783246 & 0.108067552 \\
\hline 12 & -11.888422 & 0.182734218 & 0.268691589 & 0.167278196 & 0.141190095 & -4.372180414 \\
\hline 13 & -0.214986128 & -1.611586142 & 1.972556139 & -1.4704395 & 1.201024837 & -0.399869245 \\
\hline 14 & 1.564288124 & 0.63694431 & 1.050612614 & -0.532653652 & 0.778724302 & 0.192780767 \\
\hline 15 & 0.430315807 & -0.418860675 & 0.04929488 & -0.345348435 & -1.723849754 & 2.899735928 \\
\hline 16 & -0.007106844 & -1.904352783 & -1.119167674 & 1.319502798 & 0.223633621 & 2.309346307 \\
\hline
\end{tabular}

TABLE 6: The relative importance of input parameters.

\begin{tabular}{|c|c|c|c|c|c|}
\hline \multirow{2}{*}{ Concrete property } & \multicolumn{5}{|c|}{ Relative importance of the input parameters } \\
\hline & Time (day) & Cement content $(\mathrm{kg})$ & VS content $(\mathrm{kg})$ & Water content $(\mathrm{kg})$ & SP \\
\hline Compressive strength & $32.2 \%$ & $16.2 \%$ & $14.8 \%$ & $14.9 \%$ & $21.9 \%$ \\
\hline Water permeability & $33.52 \%$ & $18.97 \%$ & $20.74 \%$ & $12.86 \%$ & $13.92 \%$ \\
\hline Porosity & $51.80 \%$ & $8.59 \%$ & $11.64 \%$ & $12.16 \%$ & $15.81 \%$ \\
\hline
\end{tabular}

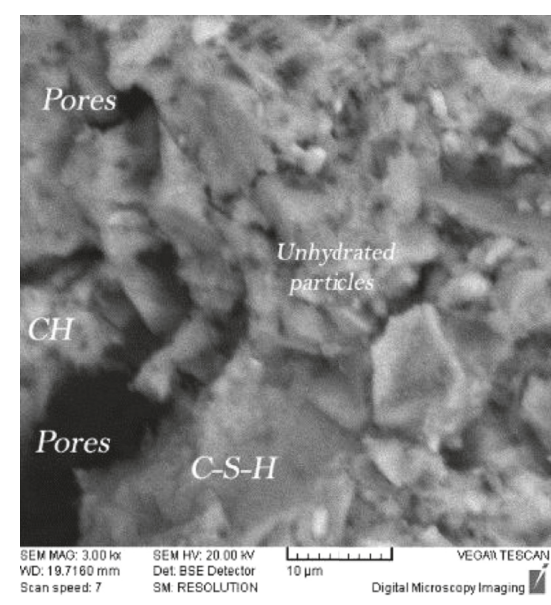

(a)

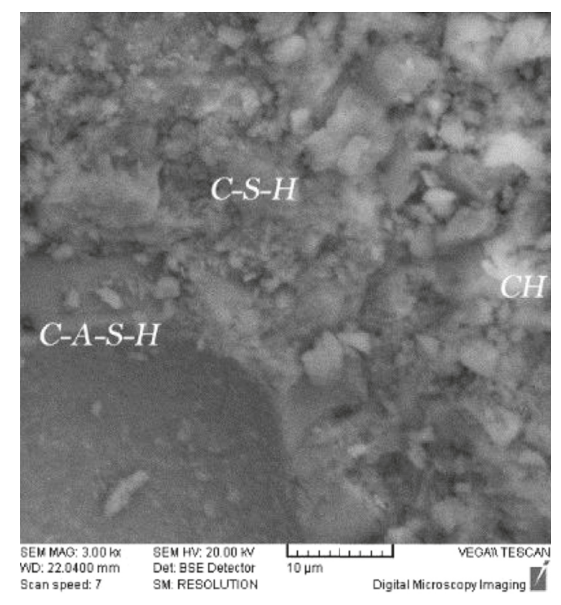

(b)

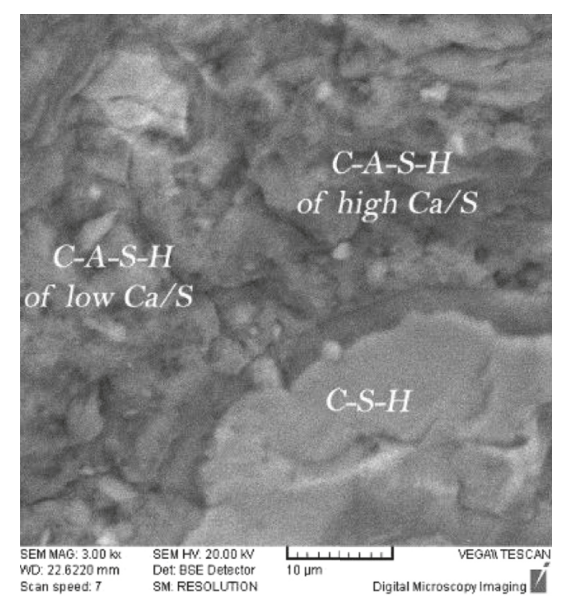

(c)

FIGURE 18: SEM of (a) 7 day-cured VS30-based paste, (b) 28 day-cured VS30-based paste, and (c) 90 day-cured VS30-based paste.

water permeability, and porosity of concretes containing volcanic scoria as cement replacement. MLR was also used for comparison. Based on the results obtained, the following conclusions can be drawn:

(1) Volcanic scoria may be more efficient in terms of its contribution to one property rather than another one. For example, volcanic scoria makes a significant contribution to reducing permeability of concrete despite the lower compressive strength.

(2) In terms of concrete durability, the binders containing $\geq 25 \%$ VS were better than the control binder and globally gave the best performance among all the replacement levels. Consequently, a significant reduction in OPC consumption and greenhouse gas 
emissions can be obtained. Therefore, incorporation of more than $25 \%$ VS can be adopted in the design of ecoconcrete.

(3) Incorporation of volcanic scoria in concrete has significant effects on the properties of concrete, particularly durability-related properties. The water penetration depth and the porosity of VS-based cement concrete demonstrated better performance as compared to plain concrete, especially at curing age of 28 days and longer.

(4) A comparison between ANN and MLR methods depicts that ANNs can be used to predict the investigated concrete properties, effectively.

(5) The values predicted by ANN models are close to the experimental results. Statistical values, such as RMSE, MAPE, $R^{2}$, and DW which are used to evaluate the feasibility of the ANN and MLR models, have demonstrated that ANN models are all accurate methods for predicting the compressive strength, water permeability, and porosity of VS-based concrete. Their higher accuracy and applicability have made them a desirable substitute for the conventional regression methods. MLR models are less accurate than the ANN ones. Therefore, by adopting ANN models, there is no need to go through timeconsuming and costly laboratory tests to obtain the investigated properties of VS-based concrete.

(6) Results have indicated that ANN models are not only practical for predicting the compressive strength but also highly efficient for predicting the water permeability and porosity of VS-based concrete. Comparison between ANN models and MLR models in terms of RMSE, MAPE, $R^{2}$, and DW statistics showed that ANNs provide better results than those of MLR in prediction of all investigated properties. For instance, $R^{2}$ values of $0.748,0.82$, and 0.829 were obtained by the MLR analysis for predicting the compressive strength, the water permeability, and concrete porosity, respectively, while these values, by contrast, were close to one in all ANNs models.

(7) Sensitivity analysis showed that all studied parameters in this work (curing time, cement content, VS content, water content, and superplasticizer content) have considerable effects on the properties of concrete containing VS as cement replacement. However, curing time was found to be the most influential parameter with relative importance of more than $30 \%$.

(8) Investigating the volcanic scoria cones that have not been exploited yet is highly recommended. In addition, making more sustainable and durable concrete using volcanic scoria is highly encouraged.

\section{Data Availability}

The data used to support the findings of this study are available from the corresponding author upon request.

\section{Conflicts of Interest}

The authors declare that there are no conflicts of interest regarding the publication of this paper.

\section{References}

[1] P. C. Aitcin and S. Mindess, Sustainability of Concrete, SponPress, London, UK, 1st edition, 2011.

[2] A. M. Brandt, Cement-Based Composites: Materials, mechanical Properties and Performance, Taylor \& Francis, Abingdon, UK, 2nd edition, 2009.

[3] P. K. Mehta and P. J. M. Monteiro, Concrete: Microstructure, Properties and Materials, McGraw-Hill, New York City, NY, USA, 3rd edition, 2006.

[4] A. M. al-Swaidani and S. D. Aliyan, "Effect of adding scoria as cement replacement on durability-related properties," International Journal of Concrete Structures and Materials, vol. 9, no. 2, pp. 241-254, 2015.

[5] P. Jahren and T. Sui, Concrete and Sustainability, CRC Press, Boca Raton, FL, USA, 2014.

[6] C. Dedeloudis, M. Zervaki, K. Sideris et al., "Natural pozzolans," in Properties of Fresh and Hardened Concrete Containing Supplementary Cementitious Materials, N. De Belie et al., Ed., RILEM State-of-the-Art Reports 25, 2018.

[7] A. A. Hammond, Pozzolana Cements for Low Cost Housing, Building and Road Research Institute, Japan, 1983.

[8] A. Al-Swaidani, "Volcanic scoria as cement replacement," in Volcanoes, G. Aeillo, Ed., Intechopen, UK, 2018.

[9] D. Graupe, Principles of Artificial Neural Networks, World Scientific, Singapore, 2nd edition, 2007.

[10] S. Khan, H. Rahmani, S. A. A. Shah, and M. Bennamoun, A Guide to Convolutional Neural Networks for Computer Vision, Morgan and Claypool, CA, USA, 2018.

[11] J. I. Kim, D. K. Kim, M. Q. Feng, and F. Yazdani, "Application of neural networks for estimation of concrete strength," Journal of Materials in Civil Engineeringg, vol. 16, no. 3, pp. 257-264, 2004.

[12] F. Khademi, S. M. Jamal, N. Deshpande, and S. Londhe, "Predicting strength of recycled aggregate concrete using artificial neural network, adaptive neuro-fuzzy inference system and multiple linear regression," International Journal of Sustainable Built Environment, vol. 5, no. 2, pp. 355-369, 2016.

[13] M. Sebastia, I. Fernandez Olmo, and A. Irabien, "Neural network prediction of unconfined compressive strength of coal fly-ash cement mixtures," Cement and Concrete Research, vol. 33, no. 8, pp. 1137-1146, 2003.

[14] F. Ozcan, C. D. Atis, D. Karahan, E. Uncuoglu, and H. Tanyildizi, "Comparison of artificial neural network and fuzzy logic models for prediction of long-term compressive strength of silica fume concrete," Advances in Engineering Software, vol. 40, no. 9, pp. 856-863, 2009.

[15] C. Bilim, C. D. Atis, H. Tanyildizi, and O. Karahan, "Predicting the compressive strength of ground granulated blast furnace slag concrete using artificial neural network," Advances in Engineering Software, vol. 40, no. 5, pp. 334-340, 2009.

[16] M. Saridemir, I. B. Topcu, F. Ozcan et al., "Prediction of long term effects of GGBFS on compressive strength of concrete by artificial neural networks and fuzzy logic," Construction and Building Materials, vol. 23, no. 3, pp. 1279-1286, 2009.

[17] V. Udhaya Kumar, B. H. Bharat Kumar, K. Balasubramanian, and T. S. Krishna Moorthy, "Applications of neural networks for concrete strength prediction," Indian Concrete Journal, vol. 2007, pp. 13-17, 2007. 
[18] S. Chithra, S. R. R. Senthil Kumar, K. Chimaraju, and F. Alfin Ashmita, "A comparative study on the compressive strength prediction models for high performance concrete containing nano silica and copper slag using regression analysis and artificial neural networks," Construction and Building Materials, vol. 114, pp. 528-535, 2016.

[19] P. Chopra, R. K. Sharma, and M. Kumar, "Prediction of compressive strength of concrete using artificial neural network and genetic programming," Advances in Materials Science and Engineering, vol. 2016, Article ID 7648467, 10 pages, 2016.

[20] M. I. Khan, "Predicting properties of high performance concrete containing composite cementitious materials using artificial neural networks," Automation in Construction, vol. 22, pp. 516-524, 2012.

[21] M. Pala, E. Ozbay, A. Oztas, and M. I. Yuce, "Appraisal of long-term effects of fly ash and silica fume on compressive strength of concrete by neural networks," Construction and Building Materials, vol. 21, no. 2, pp. 384-394, 2007.

[22] U. Atici, "Prediction of the strength of mineral admixture concrete using multivariable regression analysis and an artificial neural network," Expert Systems with Applications, vol. 38, no. 8, pp. 9609-9618, 2011.

[23] I. B. Topcu and M. Saridemir, "Prediction of compressive strength of concrete containing fly ash using artificial neural networks and fuzzy logic," Computational Materials Science, vol. 41, no. 3, pp. 305-311, 2008.

[24] B. Boukhatem, M. Ghrici, S. Kenai, and A. Tagnit-Hamou, "Prediction of efficiency factor of ground-granulated blast furnace slag of concrete using artificial neural network," ACI Materials Journal, vol. 108, no. 1, pp. 55-63, 2011.

[25] S. Subasi, "Prediction of mechanical properties of cement containing class $\mathrm{C}$ fly ash by using artificial neural network and regression technique," Scientific Research and Essay, vol. 4, no. 4, pp. 289-297, 2009.

[26] S. J. S. Hakim, J. Noorzaei, M. S. Jaafar, M. Jameel, and M. Mohammadhassani, "Application of artificial neural networks to predict compressive strength of high strength concrete," International Journal of the Physical Sciences, vol. 6, no. 5, pp. 975-981, 2011.

[27] J. Noorzaei, S. J. S. Hakim, M. S. Jaafar, and W. A. M. Thanoon, "Development of artificial neural networks for predicting concrete compressive strength," International Journal of Engineering and Technology, vol. 4, no. 2, pp. 141-153, 2007.

[28] O. A. Hodhod and H. I. Ahmed, "Modelling the corrosion initiation time of slag concrete using the artificial neural network," HBRC Journal, vol. 10, no. 3, pp. 231-234, 2014.

[29] O. A. Hodhod and H. I. Ahmed, "Developing an artificial neural network model to evaluate the chloride diffusivity in high performance concrete," HBRC Journal, vol. 9, no. 1, pp. 15-21, 2014.

[30] A. B. Goktepe, G. Inan, K. Ramyar, and A. Sezer, "Estimation of sulphate expansion level of PC mortar using statistical and neural approaches," Construction and Building Materials, vol. 20, no. 7, pp. 441-449, 2006.

[31] E. Guneyisi, M. Gesoglu, T. Ozturan, and E. Ozbay, "Estimation of chloride permeability of concretes by empirical modelling: considering effects of cement type, curing condition and age," Construction and Building Materials, vol. 23, no. 1, pp. 469-481, 2009.

[32] L. Sadowski and M. Nikoo, "Corrosion current density prediction in reinforced concrete by imperialist competitive algorithm," Neural Computing and Applications, vol. 25, no. 78, pp. 1627-1638, 2014.
[33] R. Parichatprecha and P. Nimityongskul, "Analysis of durability of high performance concrete using artificial neural networks," Construction and Building Materials, vol. 23, no. 2, pp. 910-917, 2009.

[34] H. Li and C. Lu, "Artificial neural network analysis of concrete carbonation under sustained loads," in Proceedings of International Conference on Computer Application and System Modeling, pp. 160-164, IEEE, Taiuyan, China, October 2010.

[35] H. Yasarer and Y. Najjar, "Development of a mix-design based rapid chloride permeability assessment model using neuronets," in Proceedings of International Joint Conference on neural networks, pp. 2756-2760, IEEE, CA, USA, July-August 2011.

[36] L. Yu, S. Wang, and K. K. Lai, Foreign-Exchange-Rate Forecasting with Artificial Neural Networks, Springer, Berlin, Germany, 2007.

[37] A. Toghroli, M. Mohammadhassani, M. Shariati, M. Suhartil, Z. Ibrahim, and N. H. Ramli Sulong, "Prediction of shear capacity of channel shear connectors using ANFIS," Steel and Composite Structures, vol. 17, no. 5, pp. 623-639, 2014.

[38] T. Masters, Practical neural network recipes $C^{++}$, Academic Press, Cambridge, MA, USA, 1993.

[39] J. W. Johnson, "A heuristic method for estimating the relative weight of predictor variables in multiple regression," Multivariate Behavioral Research, vol. 35, no. 1, pp. 1-19, 2000.

[40] A. M. Al-Swaidani, "Prediction of compressive strength and some permeability-related properties of concretes containing volcanic scoria as cement replacement," Romanian Journal of Materials, vol. 46, no. 4, pp. 505-514, 2016.

[41] S. Tamura and M. Tateishi, "Capabilities of four-layered feedforward neural networks: four layers versus three," IEEE Transactions on Neural Networks, vol. 8, no. 2, pp. 251-255, 1997.

[42] P. Simpson, Neural Networks Theory, Technology and Applications, IEEE, New York, NY, USA, 1996.

[43] T. Kavazoglu and P. M. Mather, "The use of backpropagating artificial neural networks in land cover classification," International Journal of Remote Sensing, vol. 24, no. 23, pp. 4907-4938, 2003.

[44] A. M. Neville, Properties of Concrete, Pearson Education, London, UK, 5th edition, 2011.

[45] D. C. Montgomery and E. A. Peck, Introduction to Linear Regression Analysis, Wiley, New York, NY, USA, 1982.

[46] A. Ferhat Bingol, A. Tortun, and R. Gul, "Neural networks analysis of compressive strength of lightweight concrete after high temperatures," Materials and Design, vol. 52, pp. 258264, 2013.

[47] M. Saridemir, "Predicting the compressive strength of mortars containing metakaolin by artificial neural networks and fuzzy logic," Advances in Engineering Software, vol. 40, no. 9, pp. 920-927, 2009.

[48] G. D. Garson, "Interpreting neural-network connection weights," AI Expert, vol. 6, pp. 47-51, 1991.

[49] A. M. al-Swaidani, "Production of more durable and sustainable concretes using volcanic scoria as cement replacement," Materiales De Construccion, vol. 67, no. 326, p. 118, 2017. 


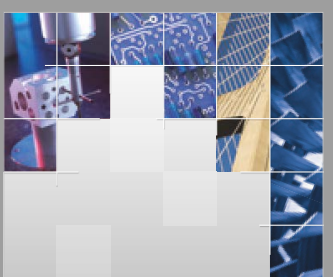

\section{Enfincering}
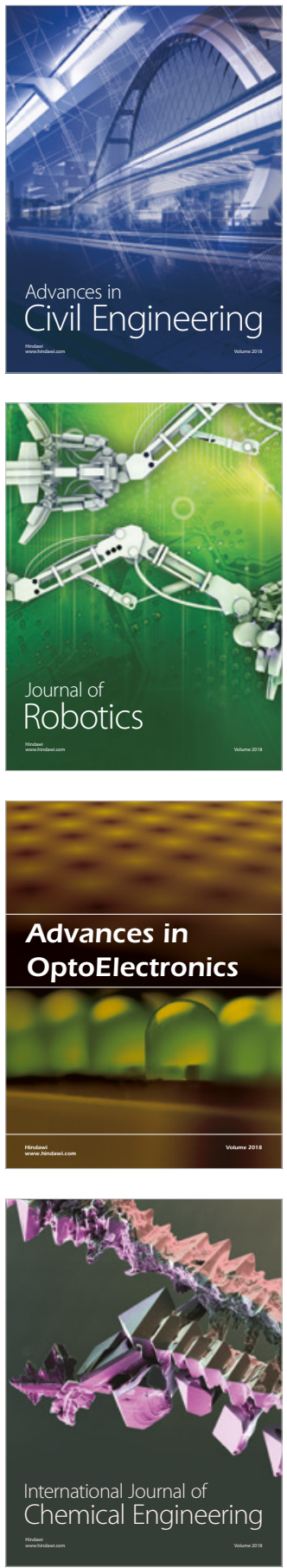

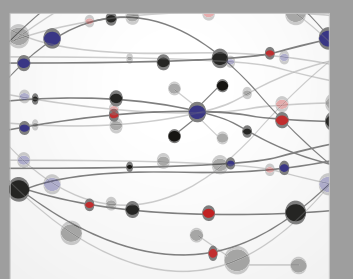

\section{Rotating \\ Machinery}

The Scientific World Journal

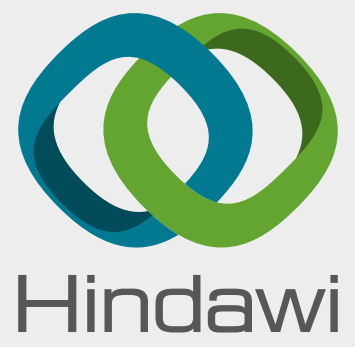

Submit your manuscripts at

www.hindawi.com
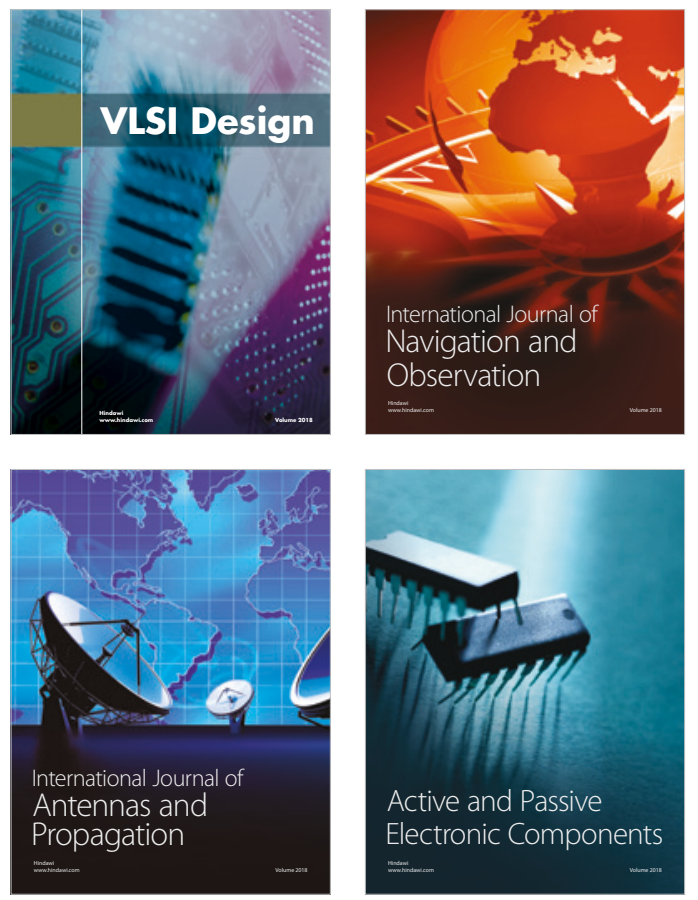
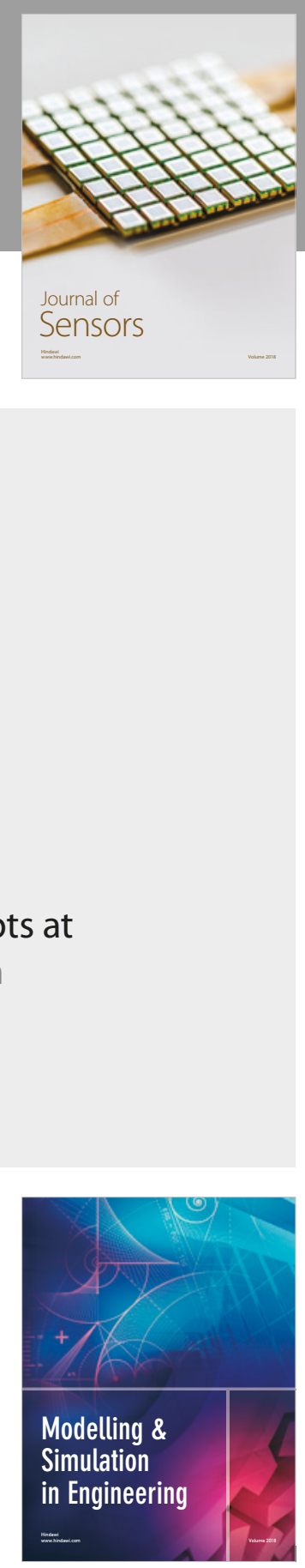

\section{Advances \\ Multimedia}
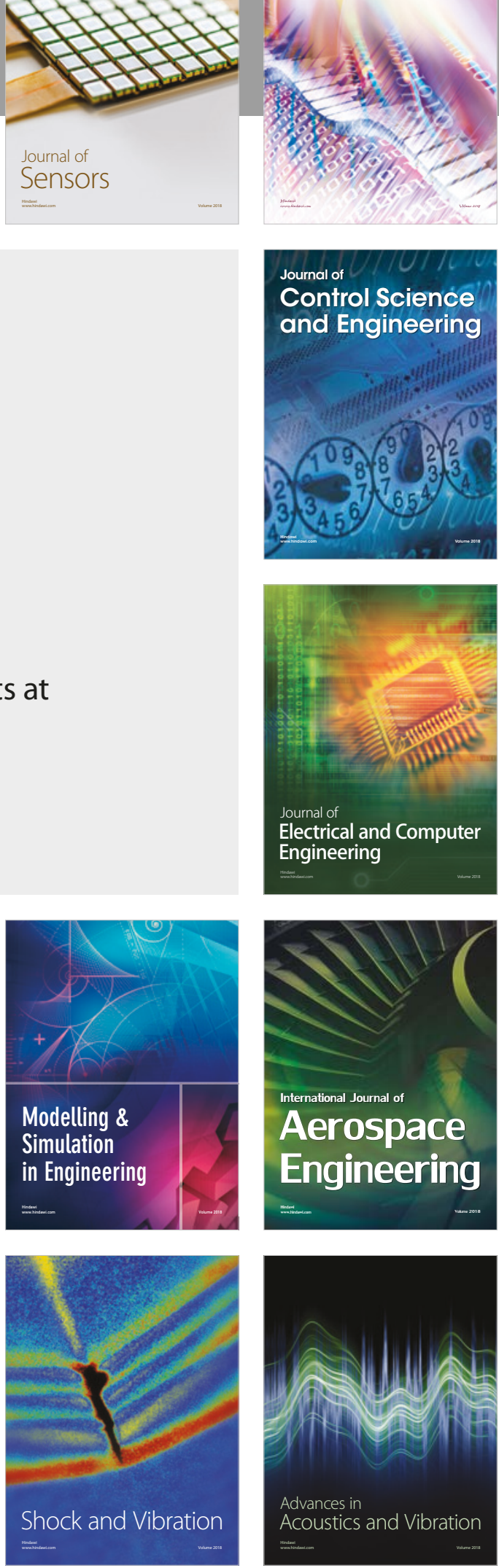